\title{
On the Financial Sustainability of Earnings-Related Pension Schemes with "Pay-As-You-Go" Financing and the Role of Government Indexed Bonds
}

\author{
David A. Robalino ${ }^{1}$ \\ András Bodor ${ }^{2}$
}

\begin{abstract}
In this paper we reconsider the idea of an earnings-related pension system with reserves invested in indexed government bonds as a mechanism to both ensure financial sustainability and improve security. The paper starts by reviewing the characterization of the sustainable rate of return of an earnings-related pension system with pay-as-you-go financing. We show that current proxies for the sustainable rate, including the Swedish "gyroscope", are not stable and propose an alternative measure that depends on the growth of the buffer-stock and the pay-asyou-go asset. Using a simple one-sector macroeconomic model that embeds a notional account pension system we then show how GDP indexed government bonds, if combined with the right measure for the sustainable rate of return on contributions, could be used to generate a sustainable and secure earnings-related pension system, without becoming a fiscal burden. The proposal is particularly attractive for countries considering reforms to earnings-related systems that have accumulated a large implicit pension debt. In this case, the government bonds allow the financing of this debt in a transparent way. The proposed mechanism can also facilitate the transition to a fully-funded pension system when the government bonds are allowed to be traded.
\end{abstract}

World Bank Policy Research Working Paper 3966, July 2006

The Policy Research Working Paper Series disseminates the findings of work in progress to encourage the exchange of ideas about development issues. An objective of the series is to get the findings out quickly, even if the presentations are less than fully polished. The papers carry the names of the authors and should be cited accordingly. The findings, interpretations, and conclusions expressed in this paper are entirely those of the authors. They do not necessarily represent the view of the World Bank, its Executive Directors, or the countries they represent. Policy Research Working Papers are available online at http://econ.worldbank.org.

The authors thank Robert Palacios, Edward Whitehouse, Michal Rutkowski, Alberto Musalem, and Robert Holzmann, for useful discussions and insights on the subject, and to Oleksiy Sluchinsky and Anca Mataoanu for commenting on early drafts of the paper.

\footnotetext{
${ }^{1}$ Senior Economist at the World Bank.

${ }^{2} \mathrm{Ph}$. D. Candidate in Economics at Georgetown University and Consultant with the World Bank.
} 


\section{Introduction}

A majority of mandatory public pension systems in the world involve an earnings-related (ER) scheme with "pay-as-you-go" financing. By earnings-related we refer to systems where the pension is essentially a function of past earnings. Three main designs can be identified: standard defined benefit systems, points systems, and notional account systems; mathematically, the three benefit formulas are equivalent. ${ }^{3}$ By pay-as-you-go we imply that pensions are financed essentially out of current contributions. Many of the systems can have reserves, but these act rather as a "buffer stock" to smooth adjustments to benefits or contribution rates that become necessary as a result of unexpected macroeconomic and/or demographic shocks or the gradual maturation of the system.

Surprisingly, in most cases, ER systems do not meet basic principles in terms of design to ensure financial sustainability, minimize distortions in labor supply and savings decisions, and to avoid arbitrary -- often regressive -- redistributions of income. Even in countries that have recently adopted notional account schemes, which deal with issues related to incentives and equity, the problem of financial sustainability has not been fully resolved.

The focus of this paper is on this last problem: the financial sustainability of the scheme. It is well known that whether an ER system is financially self-sustainable or not depends on the implicit rate of return (IRR) that it pays on contributions. If the IRR is too high, the system becomes insolvent; if the IRR is too low the system penalizes workers. Until recently, it was common to refer to the growth rate of the covered wage bill as the appropriate measure of the IRR. This is the correct measure, however, only in restrictive theoretical settings (e.g., two overlapping generation models in steady state). Reality is more complex and while the growth rate of the covered wage bill can be a good proxy under some circumstances, other factors such as retirement patterns, mortality rates, and the age-sex composition of the plan members are important as well.

\footnotetext{
${ }^{3}$ For discussions in terms of design and implementation of Notional Account systems see Holzmann and Palmer (2005), for the equivalence of benefit formulas see Robalino et al. (2005).
} 
Settergren and Mikula (2005) proposed a measure of the sustainable IRR that inspires the "automatic balancing mechanism" in the current Swedish Notional Account pension system. It depends on the growth rate of the average wage, the growth rate of reserves, and the so called "turnover duration" (TD) of the system. The TD is supposed to capture the average length of time that a monetary unit of contribution remains in the system. The authors argue that the TD multiplied by total contributions at a given point in time provides an estimate of the pension liability that can be supported by the system. We argue, however, that this measure can be arbitrary and we show that it is not bullet proof either; the system can deviate from long term equilibrium in the presence of shocks to wages and coverage rates. ${ }^{4}$

Another approach has been recently proposed in Valdez-Prieto (2005a) and applied to the case of the United States in Valdez-Prieto (2005b). The idea is to grant to the pension fund property rights over the pay-as-you-go asset (the present value of future contributions net of pension rights accruing from these contribution) through Covered Wage Bill Bonds (CWB) - which are issued by the pension fund not the government. Investors in the bonds basically acquire rights over part of future contributions. These bonds do not have maturities and investors assume 100 percent of the loss if future revenues fall below expectations. Ultimately the bonds act more as equity. The operation requires making the implicit tax on contributions (the pay-as-yougo asset) explicit. ${ }^{5}$ Then, when the bonds are traded, their resulting yields become the appropriate rate of return on contributions to guarantee financial sustainability. As pointed out by the author himself, however, the necessary arrangements to issue and trade these bonds could be quite complex, particularly for middle and low-income countries. The system's resilience to unexpected changes in survival probabilities is also a cause of concern.

In this paper we propose an alternative design for financially sustainable and secure ER systems that combines a revised formula for the sustainable IRR and the use

\footnotetext{
${ }^{4}$ There are, of course, various differences between the system description in the theoretical paper of Settergren and Mikula (2005) and the actual formulas that the Swedish pension system applies. Although the Swedish Pension System Annual Report includes a description of the system's rules, the authors needed to consult with Ole Settergren on the detailed indexation rules. The projections in this paper rely on the information gained from the correspondence with Ole Settergren.

${ }^{5}$ The "pay-as-you-go asset" concept is defined later in this paper. For additional discussions see ValdezPrieto (2005a).
} 
of government indexed bonds - an idea first introduced by Buchanan (1968). In the proposed design the latter can achieve the following objectives: (i) eliminate the risk of mismanagement of the funds that inevitably accumulate during the first couple of decades, and which are necessary to finance pensions when the system matures; (ii) improve fiscal management by making the implicit liabilities of the system explicit; (iii) improve incentives for policymakers to respect rules that ensure the long-term financial sustainability of the ER system; (iv) facilitate pension reform in countries where the ER system has accumulated a large implicit pension debt; and (v) facilitate the transition to a funded scheme if the government bonds, at some point in time, are allowed to be traded. We will see, however, that simply introducing government bonds does not guarantee financial sustainability. This is why at the same time the rules for calculating the IRR need to be reviewed.

While the proposed design could apply to any type of ER system, the focus here is on the Notional Account system. This is because the benefit formula in the NA system provides a logical and more transparent link between contributions, the IRR, and benefits, and it makes it easier to calculate and track pension liabilities (see Lindeman et al., 2006).

The paper is organized in 5 sections. Section 2 starts by characterizing the sustainable rate of return of an ER system, while showing the limitations of the Swedish approach and proposing an alternative measure. Section 3 assesses the robustness of alternative proxies for the sustainable IRR on the basis of a simple macroeconomic model that incorporates a notional account system. Section 4 is concerned with the operationalization of government indexed bonds and the assessment of fiscal impacts. Finally, Section 5 summarizes the main results of the analysis and the policy implications. A formal description of the macroeconomic model and derivations of various mathematical results are presented in the Appendices.

\section{The Sustainable Rate of Return of an ER System}

We start by defining the financing gap of an ER pension system operating in the steady state. This financing gap is defined as: 


$$
\begin{aligned}
& F G_{t}=\int_{a=f}^{L} N(a) e^{-\varphi a} l(a) \int_{b=a}^{L} \frac{l(b)}{l(a)}\left\{R(b) P(b)-(1-R(b)) \beta W_{t} w(b) e^{g(b-a)}\right\} e^{-\rho(b-a)} d b d a \\
& \text { with } P(b)=\int_{i=a}^{b}\left\{C(a)_{t}+\beta W_{t} \int_{j=a}^{i} e^{g(j-a)} w(j) e^{r^{*}(i-j)} d j\right\} G\left(i, l(.), r^{*}\right) e^{r^{*}(b-i)}\left(\frac{R(i)-R(i-1)}{R(b)}\right) d i
\end{aligned}
$$

where $f$ is the minimum age of enrollment in the system; $L$ is the maximum age that an individual biologically can live; $N(a)$ is the number of plan members born $a$ years ago; $\varphi$ is the growth rate of the population of age 0 (which reflects fertility rates); $l(a)$ is the survival probability to age $a ; R(b)$ is the share of the cohort that is retired by age $b ; P(b)$ is the average pension of all individuals in the cohort retired by age $b ; \beta$ is the contribution rate to the system; $W_{t}$ is the average covered wage at time $t ; w($.$) is the age profile of$ wages; $g$ is the growth rate of the average covered wage; $\rho$ is the discount rate (which in this case should reflect the cost of capital); $C(a)_{t}$ is the average virtual capital accumulated by an individual of cohort $a$ at time $t ; r^{*}$ is the rate used to revalorize wages and index pensions (the IRR on contributions); and G(.) is the "G factor" to transform the virtual capital into an annuity, which depends on the age of retirement, survival probabilities, and in this case the sustainable rate of return on contributions. ${ }^{6}$

The sustainable IRR can be defined as the $r^{*}$ that solves $F G()=$.0.7 There is no close form solution to this equation, but one can see that $r^{*}$ will not only depend on the growth rate of the average covered wage $(g)$ and the growth rate of the population of new borns $(\varphi)$ - which in turn affects the growth rate of the population of contributors --, but also survival probabilities and retirement patterns. To show this, Figure 1 graphs in the $\left(F G, r^{*}\right)$ space various realizations of equation (1). Each line corresponds to a combination of the growth rate of the average wage, the growth rate of the population, retirement probabilities, and the distribution of wages. The intersection of each line with the horizontal axis gives the equilibrium IRR. We see that the IRR increases with the level of economic growth, the population growth rate, and the fall in retirement

\footnotetext{
${ }^{6}$ See Appendix 1 for the derivation of $P(b)$.

${ }^{7}$ We observe that what is required is that the contributions of current plan members are enough to finance all pensions assuming that reserves are invested at market prices - captured by the rate $\rho$. One could introduce new generations into account, but this would not change the nature of the problem. In this case we are looking at a sustainable cross-sectional IRR. With new generations one would be looking at a longitudinal IRR.
} 
probabilities by age. We also notice that a high rate of economic growth makes the lines quite steep, indicating that small changes in the IRR on contributions can deviate the system from its long-term equilibrium. As a corollary, for a given IRR, a small change in the underlying macro and demographic conditions can also divert the system from equilibrium. Clearly, outside the steady state the sustainable IRR would need to change at each point in time. The question is how.

Figure 1: Financing Gap and the IRR

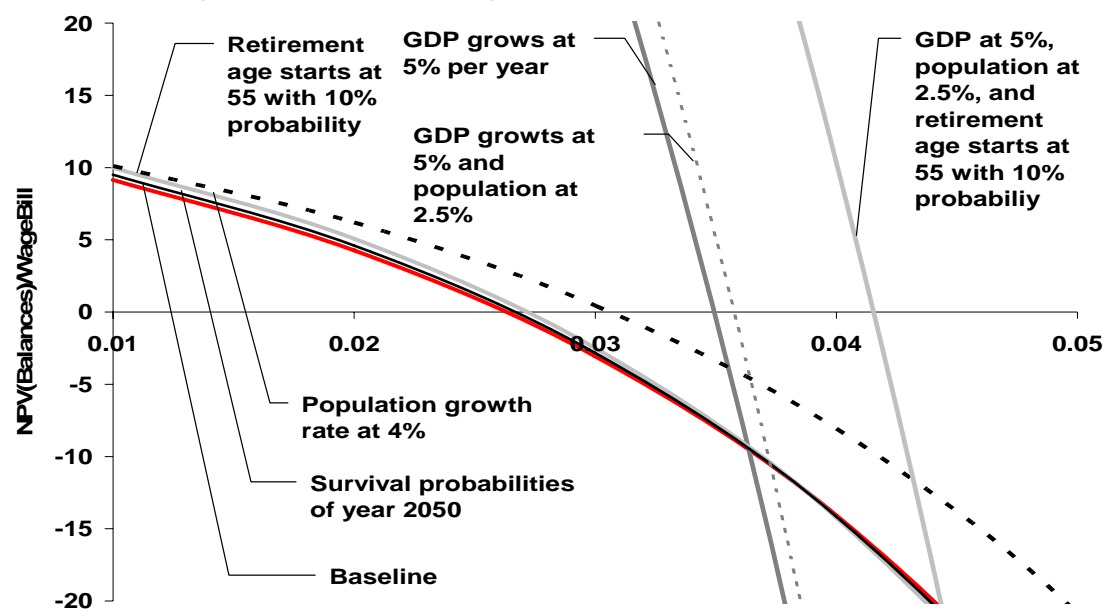

Note: The baseline scenario is built over the following assumptions: population growth of $1 \%$ per year; GDP growth of $3 \%$ per year; $2 \%$ growth in wages between ages; survival probabilities for Morocco in 2004; minimum retirement age 40 with $1 \%$ probability and maximum retirement age 75; no dropouts within age cohorts. The other lines represent deviations in one of the parameters from the baseline.

Source: Authors' calculations

The proposal developed here is based on an accounting framework "a la Swedish" -- although as shown below the actual indexation mechanism used in Sweden is not fully consistent with this underlying framework. The idea is simple: choose the IRR at each time $t$ in a way that guarantees that the liabilities of the pension system are equal to its assets. The trick then is to properly define these liabilities, and in particular, the assets of the ER pension system with pay-as-you-go financing.

The assessment of the liabilities of the system is straight forward. They are given by the present value of future pension payments to current retirees and to current contributors based on rights accrued to date. ${ }^{8}$ In the case of a notional account system the value of the IPD is easily defined. It is given by the capital accumulated in the

\footnotetext{
8 The pension system liability definition here corresponds to the "gross implicit pension debt I" definition of Holzmann, Palacios and Zviniene (2001).
} 
individual accounts plus the pensions in payment by age cohort multiplied by the annuity factor for that cohort.

The definition of assets is less intuitive. Clearly, a portion of the assets is given by the "reserves" of the pension plan - which can be equal to zero. The other part is the so called pay-as-you-go asset which is defined as the present value of future contributions minus the present value of pensions ensuing from these contributions (see Valdez-Prieto, 2005a; and Robalino and Bogomolova, 2005). The pay-as-you-go asset is positive when the implicit rate of return on contributions paid by the ER pension plan is below the rate used to discount future cash-flows. This rate can be approximated by the rate of return that the pension institution receives on the investments of the buffer fund (a market rate). The difference between this rate and the implicit rate of return on contributions can be interpreted either as the "opportunity cost" of saving in the ER plan or, put in other terms, an implicit tax on savings. Thus, in an ER system that is very generous, meaning it pays an IRR above market, the pay-as-you-go asset is negative.

Formally, in a solvent ER pension system with pay-as-you-go financing the following equality needs to hold:

$$
I P D_{t}=P A_{t}+F_{t},
$$

where $I P D_{t}$ is the implicit pension debt at time $t ; P A_{t}$ the pay-as-you-go asset and $F_{t}$ the value of the reserves (financial assets). So in summary, in a solvent pension system, the pension promises that have been made to date have to be backed by financial assets and the future contributions net of pension rights accruing from them. As discussed above, a pension plan can operate with a negative pay-as-you-go asset, but not forever.

From equation (2) it follows that given the growth rate of the pay-as-you-go asset, call it $a$, and the growth rate of the reserves, call it $r$, one can solve for the allowable growth rate of the IPD at time $t$, holding constant system, economic, and demographic conditions. It turns out that this allowable growth rate of the IPD is the IRR that the pension system can afford to pay on contributions. It is the rate by which the pension plan can revalorize wages and index pensions. Indeed, as explained before, the IPD is made of accumulated contributions plus pensions in payment multiplied by the appropriate annuity factor. So the growth rate of the IPD is given by the growth rate of the stock of contributions and the stock of pensions in payments. 
Thus, the IRR at time $t$ can then be defined as:

$$
I R R_{t}=\frac{P A_{t}}{I P D_{t}} a+\frac{F_{t}}{I P D_{t}} r+\frac{P A_{t}+F_{t}-I P D_{t}}{I P D_{t}},
$$

Hence, if one is able to obtain an accurate and simple estimate of the PA at each point in time, the expected sustainable IRR can be easily computed.

Before presenting a possible measure for the PA, we discuss how the approach proposed here to estimate the sustainable IRR differs from the Swedish system.

The analytical framework for the Swedish automatic stabilization mechanism is developed in Settergren and Mikula (2005). The authors start by dividing the crosssection financing gap of the pension system (a simplification of equation 1 ) by total contributions. In doing so, the authors indicate that they approximate the total financing gap that can be supported by one unit of contribution. The authors call this ratio the turnover duration (TD) and show, under simplifying assumptions, that the TD is equal to the money weighted average age of retirees minus the money weighted average age of contributors. The turnover duration times the contribution base then provides an estimate of what they call the contribution asset - different from the pay-asyou-go asset concept discussed above. Given information about the value of reserves, the authors calculate the "total assets" of the system. When assets are equal or above pension liabilities, contributions/pensions are revalorized/indexed by the growth rate of the covered average wage. The indexation factor for pensions is also adjusted to take into account the interest rate imputed in the calculation of the annuity factors (see next section). When assets fall below liabilities a "balancing mechanism" is activated and the growth rate of the average covered wage is multiplied by the funding ratio. Formally, we have: ${ }^{9}$

$$
I R R_{t}=\min \left\{\left(\frac{T D_{t} C_{t}+F_{t}}{I P D_{t}}\right), 1\right\}\left(\frac{W_{t}}{W_{t-1}}-1\right),
$$

\footnotetext{
${ }^{9}$ We emphasize that this description of the Swedish NDC system does not follow from the framework developed in Settergren and Mikula (2005). If one applies the framework rigorously, the rate used to revalorized accounts and index pensions would be simply given by:

$$
I R R_{t+1}=\frac{\left(T D_{t} \cdot C_{t}+F_{t}\right.}{I P D_{t}}\left(\frac{W_{t+1}}{W_{t}}-1\right)
$$
}


where $W_{t}$ is the average covered wage at time $t$. Basically, the IRR is equal to the funding ratio multiplied by the growth rate of the average covered wage. If the funding ratio falls below one, then pensions and wages are indexed by less than the growth rate of the average covered wage (at least in the initial stage of "balancing"). ${ }^{10}$

The same IRR is used to index pensions, but it is adjusted to take into account the discount rate imputed in the calculation of the annuity. Pensions are indexed by:

$$
I R R_{t}^{\prime}=\frac{\left(1+I R R_{t}\right)}{(1+i)}-1,
$$

where $i$ is the discount rate imputed in the calculation of the annuity. ${ }^{11}$

There are several issues with this proposed balancing mechanism. A first issue is that the mechanism does not follow from first principles. It is unclear why an equation such as (4) was used instead of equation (3), where PA would have been replaced by $\mathrm{TD}^{*} \mathrm{C}$. The second issue relates to the interpretation of the turnover duration. Mathematically, the TD is not a good approximation of the pay-as-go-asset, which is the relevant concept. For instance, the TD can increase as a result of an increase in life expectancy and that would be perceived as an increase in contribution assets when in fact that increase can reduce the pay-as-you-asset as individuals receive pensions for longer. It is also not clear why the TD would provide an estimate of the financing gap that can be supported by a given contribution base. It could be informative regarding the level of the financing gap, but not necessarily whether it is sustainable. Actually, if the system is solvent one would like the financing gap to be zero: liabilities would equate financial assets plus the pay-as-you-go asset. Finally, as the authors emphasize, the calculation of the TD is based on current information and the assumption of constant population growth. The TD would not capture future changes in the contribution base and therefore could overestimate or underestimate assets, thus paying an IRR on contributions that is too high or too low. In fact, Settergren (2001) admits that long-term deficits in the buffer fund can arise in the case of long-term strains on the system like

\footnotetext{
${ }^{10}$ In fact, the Swedish indexation mechanism works somewhat differently allowing the indexation to be higher than the growth rate of the average covered wage in a "recovery stage" when the balancing mechanism is active. The formula above is a simplification; however, the programming of our projections is based on the true system rules.

${ }^{11} \mathrm{i}=0.016$ under the rules of the Swedish system.
} 
negative population growth. Section 4 will show that this is indeed what happens in the presence of exogenous shocks.

If the TD is to be replaced, how would the PA be computed? In the proposed approach, computing the PA is not very different from computing the IPD - which is also required in the Sweden scheme. For the IPD, one needs estimates of G factors (annuity factors) by age. These depend on survival probabilities by age and assumptions about the future indexation of pensions (see discussion below on the discount rate used in the formula). For the PA, one needs estimates of what we call $\mathrm{Z}$ factors -- to keep similar terminologies -- that give net assets for each age cohort. These $\mathrm{Z}$ factors also depend on survival probabilities and the market discount rate, but in addition estimates of retirement/dropout probabilities, the current age profile of wages (also used for the calculation of the TD), and the expected growth rate for wages. So computing the expected PA is not more difficult than computing the TD or the IPD.

The $\mathrm{Z}$ factor for a cohort of age $i$ at time $t$, is given by:

$Z(i, t)=W_{t} w(i) \beta \sum_{a=i}^{L}\left\{\frac{l(a) y(a) d(a)}{l(i) v(i) d(i)}(\underbrace{\left(\frac{1+g}{1+\rho}\right)^{(a-i)}}_{A}-\underbrace{\frac{1}{(1+\rho)^{a-i}} \frac{\left[1+E\left(r^{*}\right)\right]^{a}}{(1+g)^{i}}\left[\frac{\left(\frac{1+g}{1+E\left(r^{*}\right)}\right)^{i}-\left(\frac{1+g}{1+E\left(r^{*}\right)}\right)^{a+1}}{1-\left(\frac{1+g}{1+E\left(r^{*}\right)}\right)}\right]\left(\left(1-\frac{v(a+1)}{v(a)}\right)+\left(1-\frac{d(a+1)}{d(a)}\right)\right)}_{B}]\right\}$

where $v(a)$ gives the probability of not being retired by age $a, d(a)$ the probability of not having dropped out of the system by age $a$, and $E\left(r^{*}\right)$ gives the expected rate of return on contributions. Basically, expression $A$ captures the present value of contributions paid at age $a$, and expression $B$ the pensions (and lump sum) paid to new retirees (and dropouts) at age $a .{ }^{12}$ Then the pay-as-you-go asset at time $t$ is:

$$
E\left(P A_{t}\right)=\sum_{a=f}^{L} N(a, t) Z(a, t)+\sum_{k=t+1 b=f}^{T} \sum^{L} \Delta N(b, k) Z(b, k),
$$

where $N(a, t)$ are the contributors of age a at time $t, d N(b, k)$ the new entrants of age $b$ at time $k$, and $T$ the planning horizon.

One can argue that having estimates of future entrants, the growth rate of the average wage, and the expected rate or return on contributions is complicated. The

\footnotetext{
${ }^{12}$ See Appendix 1 for the derivation of $Z(i, t)$.
} 
proposal developed here assumes that past trends hold. The $E\left(r^{*}\right)$ is estimated by an average of past IRRs and new contributors by age can be projected given past information on new entrants and their age distribution. A virtue of the PA is that it is forward looking. Basically, it tries to anticipate the effects of shocks that occur today on the future flows of net contributions. Clearly, the past is not necessary a good predictor of the future. Hence, when calculating the PA of a system in year 2005, one would miss the impact of unknown phenomena that take place, say, one decade from now. Let us assume, for instance, that the unknown shock is a permanent drastic drop in coverage rates that takes place suddenly - unannounced. Estimates of the PA in the years prior to the shock would overestimate its true value (i.e., wages and pensions would be revalorized/indexed by a rate that is too high). Nonetheless, as soon as the shock takes place, and the system identifies that is permanent, its short and long-term effects would be incorporated in the calculation of the IRR, making up for previous over adjustments. We also emphasize that those shocks that take place far into the future have small impact in the current value of the PA.

\section{Computing annuities and indexing pensions ${ }^{13}$}

There is an important precision to be made regarding the calculation of annuity factors and the type of indexation mechanism used for pensions. Often decisions at these two levels are disconnected and, as shown in Section 4, this is problematic for an NA system without the appropriate stabilization mechanism.

If in practice pensions are going to be indexed by the IRR (or rough proxies such as wages or GDP growth rates), which is also the rate used to revalorize wages, then the annuity factor should not incorporate a discount rate. In other words, the pension would be simply equal to the notional capital accumulated in the individual account divided by the life expectancy at retirement. On the contrary, if pensions are solely going to be indexed by prices, the annuity factor should incorporate in the calculation the expected IRR. Basically, if pensions are only going to be indexed by prices then they should be higher from the start. If they are going to be indexed by the IRR then they

\footnotetext{
${ }^{13}$ This is not an issue if the public pension system only manages the accumulation phase and then outsources the issuance of annuities. Basically, upon retirement individuals would receive a lump sum and then have the mandate to purchase an annuity in the private sector. Alternatively, the pension fund could conduct biddings among private sector providers to allocate cohorts of annuitants.
} 
should be smaller.

To see this it is useful to consider the case of an NA system in a steady state where the sustainable IRR $\left(r^{*}\right)$ is known and where there is no inflation. Thus, contributions are revalorized by this rate and pensions can grow at this rate, meaning they should be discounted by this rate as well. ${ }^{14}$ Hence, if there is no indexation, the pension at age $R, p_{R}$, solves:

$$
\left[\beta w_{f} \sum_{a=f}^{R}(1+g)^{a-f}\left(1+r^{*}\right)^{R-a}\right]=p_{R} \sum_{b=R+1}^{M a x} \frac{s(R, b)}{\left(1+r^{*}\right)^{b-R}},
$$

where $s(R, b)$ is the survival probability between ages $R$ and $b$. The pension will be given by the accumulated contributions (expression in brackets) divided by an annuity factor that does incorporate $r^{*}$ as the discount rate.

If pensions are indexed, the pension at age $R$ should solve:

$$
\left[\beta w_{f} \sum_{a=f}^{R}(1+g)^{a-f}\left(1+r^{*}\right)^{R-a}\right]=p_{R} \sum_{b=R+1}^{M a x} \frac{\left(1+r^{*}\right)^{b-R} s(R, b)}{\left(1+r^{*}\right)^{b-R}},
$$

In this case the growth rate and the discount rate cancel out and the pension is computed by dividing the accumulated capital by life expectancy.

In both cases, the $r^{*}$ becomes the IRR received by individuals and, as shown in Robalino et al. (2005), this rate does not depend on wages and contributions histories. In the first case the pension is higher from the start but it is not indexed in real terms. In the second case, it is lower but it is indexed.

What happens if the annuity is computed using (8) but pensions are not indexed (in real terms). In this case the pension would be too low relative to the contributions and therefore the implicit rate of return received by the individuals would be lower. Indeed, the discount rate necessary to make the present value of contributions and pensions flows equal would need to be lower. On the contrary, if the annuity is computed using (7) and pensions are also indexed (in real terms), individuals would be receiving an IRR that is too high (and therefore unsustainable). In fact, it is possible to define the correct indexation factor $\pi$ given the sustainable IRR and the discount rate $i$ used in the calculation of the pension. Factor $\pi$ needs to solve:

\footnotetext{
${ }^{14}$ Indeed, the relevant question is how one monetary unit of a pension in the future is worth today.
} 


$$
\sum_{b=R+1}^{\operatorname{Max}}\left(\frac{C_{R}}{\sum_{b=R+1}^{M a x} s(R, b)(1+i)^{-(b-R)}}\right) \frac{(1+\pi)^{(b-R)} s(R, b)}{(1+I R R)^{(b-R)}}=C_{R^{\prime}}
$$

Where $C_{R}$ is the capital accumulated in the individual account at the time of retirement. The expression in brackets is the value of the initial pension calculated on the basis of a discount rate $i$. Equation (9) states that if, ex-post, the pension is going to be indexed by $\pi$ the present value should still be equal to $C_{R}$. It is easy to show that for equation (9) to hold, the following needs to be verified for any $b$ :

$$
\begin{aligned}
& \frac{1+\pi}{1+I R R}=\frac{1}{1+i} \\
& \Leftrightarrow \pi=\left(\frac{1+I R R}{1+i}\right)-1
\end{aligned}
$$

Clearly, if the IRR itself is not sustainable, then this correction will not solve the problem of financial sustainability. Figure 2 graphs $\pi$ as a function of $i$, for $\operatorname{IRR}=3 \%$. Cases below the line pay to individuals implicit rates of return on contributions which are below the sustainable IRR. Cases, above the line pay implicit rates of return that are above the sustainable IRR. 
Figure 2: Annuity Factors, Discount Rates, and Indexation Policy

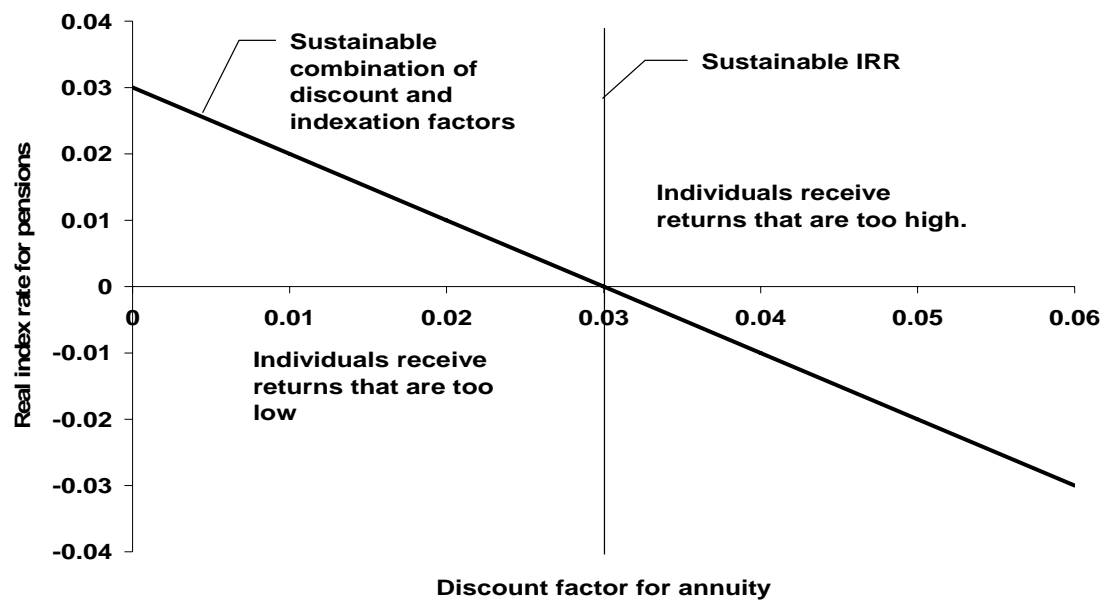

Note: The line plots simply the tradeoffs between the discount rate and the indexation factor required to reproduce the sustainable IRR, in this case fix at $3 \%$.

Source: Author's calculations.

In practice, policy makers face these choices, but given uncertainty the answer is often less straightforward. Introducing a discount factor in the calculation of the annuity is a way to guarantee higher pensions up front. The discount factor, however, can be too high to be sustainable.

If the system incorporates a stabilization mechanism such as equation (3), then there is flexibility in terms of whether or not a discount factor is used in the calculation of the annuity. Indeed, the stabilization mechanism will ensure that the IRR that is used to revalorize wages and index pensions after the discount factor was taken into account brings the pension system to a sustainable path. The higher the discount rate used in the calculation of the annuity, the lower the IRR that the system will pay (i.e., the lower the rate used to revalorize and index pensions). If no discount factor is used, then the system will pay the maximum IRR other things being constant. Because the IRR is the rate that should be used to discount the flow of contributions and pensions, this approach ensures that all individuals within a given age-cohort receive the same implicit rate of return on their contributions - albeit one that moves over time - regardless of wages and contributions histories.

With no stabilization mechanism, however, the discount factor might be too high relative to the allowable IRR - which as seen before changes over time - and it will not 
be possible to correct. This is shown in Section 4. One alternative in this case, is not to include a discount factor in the calculation of the annuity, but to guarantee full indexation of pensions on the basis of the system IRR. In Appendix 2 we show, however, that under general conditions individuals - at least those who have limited access to financial markets and face stringent borrowing constraints - would be better off if a discount rate is introduced up front and the pensions are indexed by prices.

\section{Simulating the robustness of alternative rules for the IRR of the system}

To study the dynamics of an ER pension system with pay-as-you-go financing under alternative rules for the IRR, we use a simple one sector macro model that incorporates a notional account pension scheme (see Appendix 3 for a formal description). For simplicity, and given that the focus is to analyze the dynamics of the IRR, economic growth and the savings rate of the economy are exogenous in the model. Future extensions should study the behavior of the pension system with endogenous savings. The dynamics of wages and the market interest rate, on the other hand, are endogenous in our model. This model provides a mechanism to ensure internal consistency regarding changes in pension system design, macroeconomic trends and demographic trends. For instance, simulated fluctuations in GDP growth will affect the pension system through changes in wages and the interest rate - a recession is accompanied by higher interest rates. Similarly, retirement and survival probabilities will affect the economy through a change in the size and age composition of the labor force, which in turn affects wages and the interest rate. Coverage and labor supply, however, are not affected by changes in the macroeconomy or pension system parameters.

We use the model to understand how various rules for the evolution of IRR on contributions affect the dynamics of the pension system. In particular, cash balances and reserves levels. If the earnings-related system is financially self-sustainable, then the value of reserves should never be negative - or at least not for an extended period of time.

We consider 6 rules to determine the IRR across a large number of economic and demographic scenarios: (i) wages are revalorized by the growth rate of the average 
covered wage and pensions are indexed by prices (i.e., growth is zero in real terms); (ii) the IRR is equal to the growth rate of the average covered wage and it applies to wages and pensions; (iii) the IRR is equal to the growth rate of the covered wage bill; (iv) the IRR is equal to the growth rate of GDP; (v) the IRR is based on the Swedish system (equation 4); and (vi) the IRR is based on the proposal developed in this paper (equation 3). ${ }^{15}$ We also take into account two different methods to compute the annuity; with and without a discount factor.

As for the scenarios, we consider combinations of eight blocks of variables: (i) population growth; (ii) GDP growth; (iii) retirement probabilities; (iv) drop-out/reentry probabilities; (v) survival probabilities; (vi) productivity by age; (vii) inflation and interest rates; and (viii) the coefficient of human capital in the production function. Basically, each of these variables/groups of variables is allowed to be in one out of three states. ${ }^{16}$ The various states are described in Table 1 and have been selected to put the pension system under high stress and assess its resilience. The deviations from state 1 can be considered as shocks to the system. As a general rule, they are introduced at a point in time when the system has already reached a great degree of maturity.

\footnotetext{
${ }^{15}$ A paper by Lindeman et al. (2005) had analyzed the first 3 rules (with alternative combinations for wages and pensions), but outside a macro framework. The analysis here confirms some of the findings.

${ }^{16}$ The probability of state 1 occurring is $50 \%$ for each of the blocks of variables. The probability of state 2 or 3 occurring is $25 \%$ respectively for each of the blocks of variables.
} 
Table 1: State for Key Model Variables

\begin{tabular}{|c|c|c|c|}
\hline Variable(s) & State 1 - Baseline & State 2 & State 3 \\
\hline $\begin{array}{l}\text { Growth of } \\
\text { population of } \\
\text { new born }\end{array}$ & $\begin{array}{l}\text { Constant population }(0 \% \\
\text { growth of population of } \\
\text { new born.) }\end{array}$ & $\begin{array}{l}\text { Population of new born } \\
\text { initially remains constant, } \\
\text { then decreases at an } \\
\text { annual } 0.5 \% \text { rate between } \\
\text { years } 50 \text { and } 150 \text {, then it } \\
\text { grows at } 0.5 \% \text { per year } \\
\text { beyond year } 150 .\end{array}$ & $\begin{array}{l}\text { Population of new born } \\
\text { initially remains constant, } \\
\text { then it gets on a steady } \\
\text { decreasing path at an } \\
\text { annual } 0.5 \% \text { rate beyond } \\
\text { year } 50 .\end{array}$ \\
\hline GDP growth & $\begin{array}{l}\text { Real GDP grows at } 2.5 \% \\
\text { per year. }\end{array}$ & $\begin{array}{l}\text { Real GDP grows at } 2.5 \% \\
\text { per year, then increases to } \\
7 \% \text { in year } 150, \text { then falls to } \\
1 \% \text { in year } 165 .\end{array}$ & $\begin{array}{l}\text { Real GDP grows at } 2.5 \% \\
\text { per year, then a recession } \\
\text { hits in year } 150(-5 \% \text { per } \\
\text { year). The economy } \\
\text { recovers growth of } 2.5 \% \text { in } \\
\text { year } 155 \text {. }\end{array}$ \\
\hline $\begin{array}{l}\text { Retirement } \\
\text { probabilities }\end{array}$ & $\begin{array}{l}\text { Probability is zero up to } \\
\text { age } 39 \text { then it increases } \\
\text { linearly from } 1 \% \text { at age } 40 \\
\text { to } 100 \% \text { at age } 75 .\end{array}$ & $\begin{array}{l}\text { Like state } 1 \text {, but } \\
\text { probability of retirement at } \\
\text { age } 40 \text { increases from } 1 \% \\
\text { to } 30 \% \text { in year 150; for } \\
\text { other ages it is adjusted } \\
\text { accordingly. }\end{array}$ & $\begin{array}{l}\text { Like state } 2 \text {, but the } \\
\text { increase in the initial } \\
\text { retirement probability } \\
\text { does not happen through } \\
\text { an immediate shock, but } \\
\text { over a } 30 \text { year period. }\end{array}$ \\
\hline $\begin{array}{c}\text { Dropout/reentry } \\
\text { probabilities }\end{array}$ & $\begin{array}{l}\text { Dropout probabilities are } \\
\text { zero at all ages. }\end{array}$ & $\begin{array}{l}\text { Dropout probability for all } \\
\text { ages suddenly increases to } \\
30 \% \text { in year } 150 \text { and then } \\
\text { falls to } 20 \% \text { in year } 155 \text {. } \\
\text { The reentry probability is } \\
10 \% \text {. }\end{array}$ & $\begin{array}{l}\text { Dropout probability for all } \\
\text { ages suddenly increases to } \\
30 \% \text { in year } 150 \text { and then } \\
\text { fall to } 20 \% \text { in year } 160 . \\
\text { The reentry probability is } \\
10 \% \text {. }\end{array}$ \\
\hline $\begin{array}{c}\text { Survival } \\
\text { probabilities }\end{array}$ & $\begin{array}{l}\text { Survival probabilities are } \\
\text { constant over time at levels } \\
\text { observed in Morocco } \\
\text { today. }\end{array}$ & $\begin{array}{l}\text { Survival probabilities } \\
\text { increase to } 1.5 \text { times the } \\
\text { expected } 2050 \text { levels for } \\
\text { Morocco by year } 150 \text { of the } \\
\text { simulation. }\end{array}$ & $\begin{array}{l}\text { Survival probabilities } \\
\text { increase to twice the } \\
\text { expected } 2050 \text { levels for } \\
\text { Morocco in year } 150 \text { of the } \\
\text { simulation. }\end{array}$ \\
\hline $\begin{array}{l}\text { Productivity by } \\
\text { age }\end{array}$ & $\begin{array}{l}\text { Productivity increases at } \\
2 \% \text { for each year of age. }\end{array}$ & $\begin{array}{l}\text { Productivity increases } \\
\text { initially at } 2 \% \text { and then } \\
\text { increases from } 2 \% \text { to } 4 \% \\
\text { between years } 100 \text { and } 110 \text {. }\end{array}$ & $\begin{array}{l}\text { Productivity increases } \\
\text { initially at } 4 \% \text { and drops } \\
\text { from } 4 \% \text { to } 1 \% \text { between } \\
\text { years } 100 \text { and } 110 .\end{array}$ \\
\hline $\begin{array}{l}\text { Inflation and } \\
\text { interest rates }\end{array}$ & $\begin{array}{l}\text { Inflation at } 2 \% \text {. Real rate } \\
\text { of return on reserves equal } \\
\text { to } 30 \% \text { of marginal } \\
\text { productivity of capital. } \\
\text { Discount rate and rate } \\
\text { used to compute annuity } \\
\text { set equal to long term GDP } \\
\text { growth rate. Marginal } \\
\text { return on capital equal to } \\
1.25 \text { times GDP growth. }\end{array}$ & $\begin{array}{l}\text { Inflation at } 2 \% \text {. Real rate } \\
\text { of return on reserves equal } \\
\text { to } 60 \% \text { of marginal } \\
\text { productivity of capital. } \\
\text { Discount rate and rate } \\
\text { used to compute annuity } \\
\text { set equal to long term GDP } \\
\text { growth rate. Marginal } \\
\text { return on capital equal to } \\
1.25 \text { times GDP growth. }\end{array}$ & $\begin{array}{l}\text { Inflation at } 2 \% \text {. Real rate } \\
\text { of return on reserves equal } \\
\text { to } 60 \% \text { of marginal } \\
\text { productivity of capital. } \\
\text { Discount rate and rate } \\
\text { used to compute annuity } \\
\text { set equal to long term GDP } \\
\text { growth rate. Marginal } \\
\text { return on capital equal to } 2 \\
\text { times GDP growth. }\end{array}$ \\
\hline $\begin{array}{l}\text { Coefficient of } \\
\text { human capital }\end{array}$ & $\begin{array}{l}\text { Coefficient of human } \\
\text { capital equal to } 0.5 \text {. }\end{array}$ & $\begin{array}{l}\text { Coefficient of human } \\
\text { capital equal to } 0.1 \text {. }\end{array}$ & $\begin{array}{l}\text { Coefficient of human } \\
\text { capital equal to } 0.8 \text {. }\end{array}$ \\
\hline
\end{tabular}

Initial population of new born is 1,000. Initial GDP per capita is 100 units. Initial level of capital is calibrated to achieve targeted, long term, marginal return on capital. Minimum age to enter the labor force (f) set at 20 years

We discuss the results of the simulations in three parts. First, we look at the dynamics of funds reserves under each of the rules for the IRR across a random sample of 100 scenarios evolving over a period of 300 years. Then, for each of the indexation 
rules, we look at the distribution of the following outputs: (i) the value of the reserves as a share of GDP in year 150 and year 300; (ii) the value of the cash-balance as a share of GDP in year 150 and in year 300; (iii) the average IRR for the period $t \in[150,300]$; and (iv) the maximum value of the reserves as a share of GDP during the entire simulation period. Finally, we analyze the sensitivity of the steady level of fund reserves and the IRR to changes in selected model variables.

We first discuss the simulations where the calculation of the annuity factor does not include a discount rate. The results show that only the new proposal developed in this paper and the "price indexation mechanism" -- that is salaries (contributions) revalorized by the growth rate of the covered average wage and pensions indexed by inflation -- are capable of avoiding extended periods of negative reserves (see Figure 3). Like the other revalorization/indexation mechanisms, however, price indexation is not stable in the sense that for some of the scenarios assets (reserves) accumulate without bound. This implies that the system is penalizing workers by paying an IRR below the sustainable level, essentially, a higher implicit tax on savings than what the system the system requires.

This being said, none of the indexation mechanisms are systematically unsustainable when the annuity is calculated without discounting, simply because there is "more room" in this case to index pensions. The average value of reserves over the 100 random combinations of states is positive for all the 6 indexation mechanisms both at year 150 and 300. The mean cash balance is positive for all the indexation mechanisms at year 300, and positive or slightly negative at year 150 when some of the shocks take effect (see Table 2).

The Swedish mechanism clearly outperforms the average wage growth, the covered wage bill growth and the GDP growth indexation mechanisms in terms of keeping positive system's reserves. However, the Swedish system exhibits a tendency to over accumulate assets in case of positive population growth and the balancing mechanism is vulnerable against a shrinking population as well. (See the Appendix 4 for a comprehensive comparative sensitivity analysis of the Swedish system and the new proposal including various population growth scenarios.). Indeed, several combinations 
of states that include long-term negative population growth put the Swedish system onto an unsustainable path.

As pointed out already, the inflation adjustment rule does not show weakness towards system sustainability, as pensions are indexed, on average, by an IRR below the sustainable level. In fact, price indexation displays a high variance in the level of reserves. The protection against "system bankruptcy" therefore comes at the cost of high implicit taxes on savings.

The proposal developed in this paper is the only mechanism that avoids extended periods with negative reserves and converges towards a sustainable steadystate in all the scenarios. 
Figure 3: Dynamics of the Reserves/GDP Ratio When Annuity Does Not Include a Discount Rate

Prices
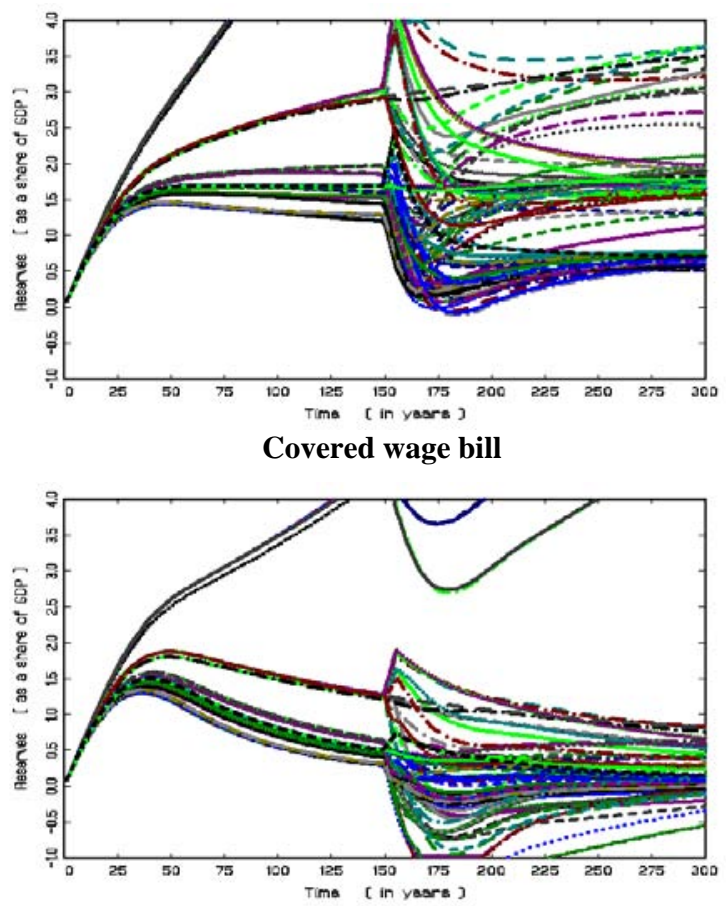

Swedish system

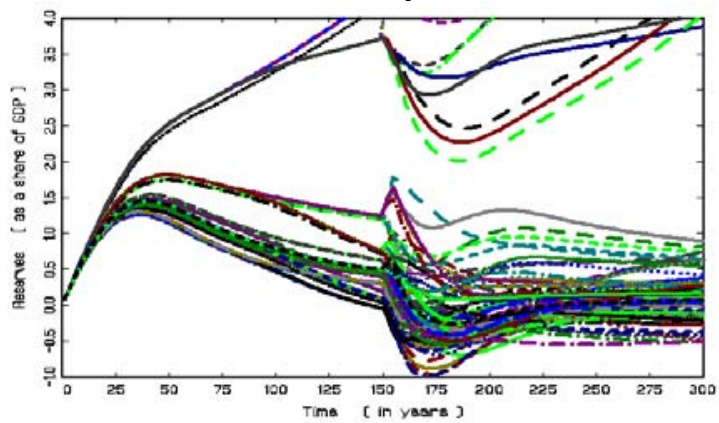

Covered average wage

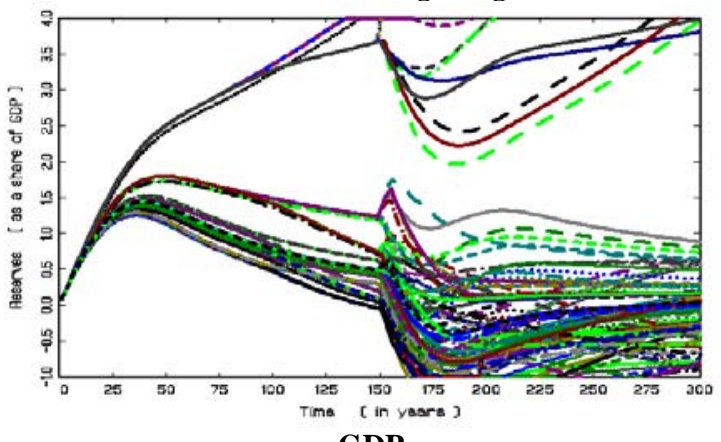

GDP

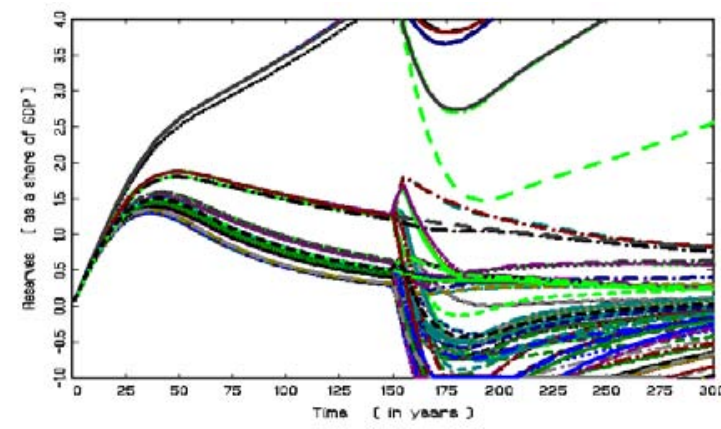

Equation (3)

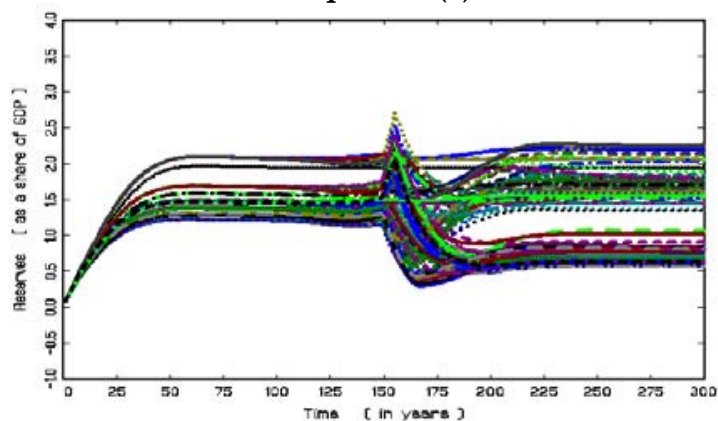

Source: Author's calculation.

When a discount rate is introduced in the calculations of the annuity the results are very different (see Figure 4). ${ }^{17}$ The average wage growth, the covered wage bill growth and the GDP growth indexation mechanisms become unsustainable in all the scenarios. This is not very surprising because the inclusion of the discount rate in the calculation of the annuity factor results in higher initial values for pensions, and these higher initial pensions are adjusted through identical proportional increases as in the case of no discount factor in the annuity calculation. In the case of average wage, wage

${ }^{17}$ The discount rate that we use is equal, as is the standard assumption, to the long-term growth rate of GDP. 
bill, and GDP indexation pensions are essentially indexed twice. First, ex-ante, at the time of calculating the pension - since the annuity factor already incorporates a discount (i.e., indexation) factor - then each time pensions are paid. Price indexation behaves better since, as discussed in the previous section, the calculation of the annuity with a discount factor (expressed in real terms), is a consistent with price indexation. The problem is that the discount rate used in the calculation of the annuity factor is not necessarily the sustainable rate. Price indexation therefore struggles with the higher level of initial pensions without any mechanism for correction.

Only the Swedish indexation mechanism and the new proposal based on equation (3) are equipped to adjust to this difference in the use of the discount factor in the calculation of the annuity. The Swedish mechanism, when the balancing mechanism is not activated, behaves like price indexation if the growth rate of the average wage is equal to the discount rate used in the calculation of the annuity factor. The stabilization mechanism, however, is not sufficient to deal with periods of negative population growth rate and therefore there are still scenarios where the reserves of the system become negative

The rule proposed in this paper, on the other hand, never generate negative reserves levels and converge in all cases to a stable steady state. In part this is because the proposed algorithm also takes into account the impact of the discount rate in the pay-as-you-go asset (i.e., other things being equal, the higher the discount rate the lower the pay-as-you-go asset). 
Figure 4: Evolution of the Reserves/GDP Ratio when the Annuity Includes a Discount Rate Prices
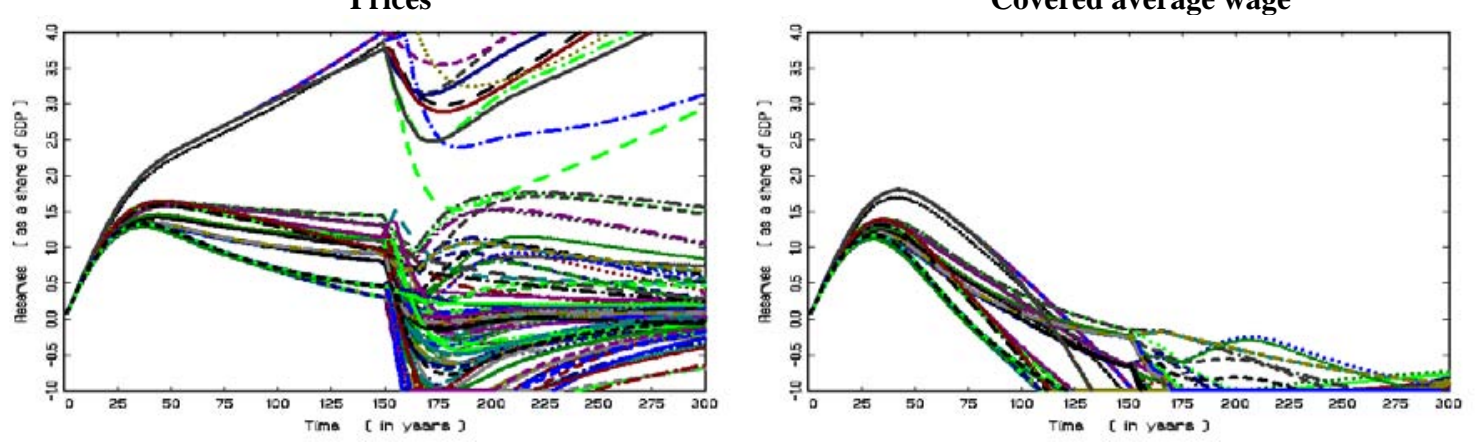

Covered wage bill
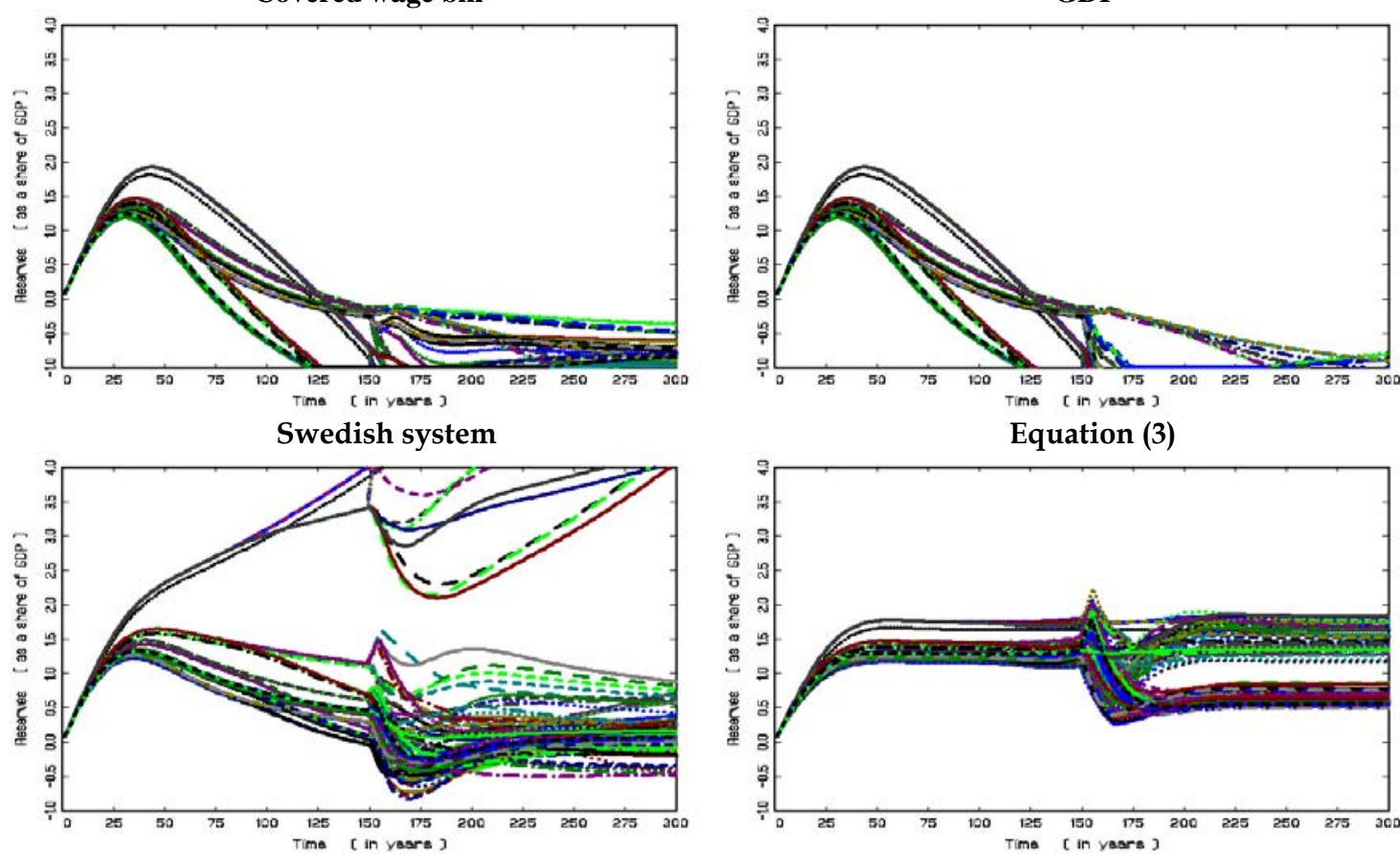

The discount rate used in the calculation of the annuity is equal to the long-term growth rate of the economy. Source: Author's calculations.

To gain more insights into the results of the simulations, we look at summary statistics for key output variables (see Table 2). There are several interesting observations. First, the mechanism proposed in this paper and the price indexation mechanisms are the only ones capable of insuring positive reserves level at the end of the simulation horizon. Even the Swedish system would run into debt by year 300 in the amount of $57.2 \%$ of GDP under the worst set of "environment conditions." We also observe that both the range and the variance of level of reserves are the smallest under the indexation rule following equation (3). The proposed mechanism is capable to "downward adjust" the IRR in straining situations, but even these straining set of 
circumstances did not push the IRR into the negative. It is an important message of the simulation because, conceptually, negative IRR paths could be consistent with equation (3) under certain circumstances. These, however, would be difficult to implement at the practical level.

Table 2: Descriptive Statistics for Selected Outputs

\begin{tabular}{|c|c|c|c|c|c|c|c|c|}
\hline & \multicolumn{4}{|c|}{ Annuity calculated with discounting } & \multicolumn{4}{|c|}{ Annuity calculated without discounting } \\
\hline & Mean & Stdev & Min & Max & Mean & Stdev & Min & $\operatorname{Max}$ \\
\hline \multicolumn{9}{|l|}{ Average wage } \\
\hline Reserves/GDP $t=150$ & -1.326 & 0.698 & -2.480 & -0.146 & 0.918 & 1.283 & -0.050 & 4.341 \\
\hline Reserves/GDP $t=300$ & -3.390 & 3.514 & -17.241 & -0.728 & 0.761 & 2.331 & -1.301 & 8.856 \\
\hline Balance/GDP $t=150$ & -0.031 & 0.013 & -0.046 & -0.009 & -0.002 & 0.006 & -0.008 & 0.004 \\
\hline Balance/GDP $t=300$ & -0.022 & 0.017 & -0.065 & 0.001 & 0.000 & 0.006 & -0.012 & 0.013 \\
\hline Average IRR (to year 300) & 0.021 & 0.005 & 0.009 & 0.032 & 0.021 & 0.005 & 0.009 & 0.032 \\
\hline \multicolumn{9}{|l|}{ Wage bill } \\
\hline Reserves/GDP $t=150$ & -0.959 & 0.561 & -1.689 & -0.124 & 1.180 & 1.400 & 0.277 & 4.823 \\
\hline Reserves/GDP $t=300$ & -2.765 & 3.036 & -15.027 & -0.366 & 1.207 & 2.644 & -0.557 & 9.164 \\
\hline Balance/GDP $t=150$ & -0.023 & 0.010 & -0.030 & -0.009 & 0.004 & 0.000 & 0.003 & 0.004 \\
\hline Balance/GDP $t=300$ & -0.020 & 0.013 & -0.044 & -0.004 & 0.002 & 0.001 & 0.001 & 0.004 \\
\hline Average IRR (to year 300) & 0.025 & 0.006 & 0.016 & 0.038 & 0.025 & 0.006 & 0.016 & 0.038 \\
\hline \multicolumn{9}{|l|}{ GDP } \\
\hline Reserves/GDP $t=150$ & -0.959 & 0.561 & -1.689 & -0.124 & 1.180 & 1.400 & 0.277 & 4.823 \\
\hline Reserves/GDP $t=300$ & -3.255 & 3.150 & -15.027 & -0.794 & 0.850 & 2.535 & -1.993 & 9.164 \\
\hline Balance/GDP $t=150$ & -0.023 & 0.010 & -0.030 & -0.009 & 0.004 & 0.000 & 0.003 & 0.004 \\
\hline Balance/GDP $t=300$ & -0.020 & 0.013 & -0.044 & -0.004 & 0.002 & 0.001 & 0.001 & 0.004 \\
\hline Average IRR (to year 300) & 0.022 & 0.004 & 0.016 & 0.025 & 0.022 & 0.004 & 0.016 & 0.025 \\
\hline \multicolumn{9}{|l|}{ Inflation } \\
\hline Reserves/GDP $t=150$ & 1.191 & 1.142 & 0.297 & 4.058 & 2.706 & 2.113 & 1.146 & 8.115 \\
\hline Reserves/GDP $t=300$ & 0.928 & 2.102 & -0.691 & 8.262 & 3.734 & 5.657 & 0.509 & 19.952 \\
\hline Balance/GDP $t=150$ & 0.005 & 0.009 & -0.007 & 0.020 & 0.024 & 0.003 & 0.019 & 0.028 \\
\hline Balance/GDP $t=300$ & 0.001 & 0.002 & -0.003 & 0.008 & 0.016 & 0.009 & 0.004 & 0.033 \\
\hline Average IRR (to year 300) & 0.021 & 0.005 & 0.009 & 0.032 & 0.021 & 0.005 & 0.009 & 0.032 \\
\hline \multicolumn{9}{|l|}{ Swedish mechanism } \\
\hline Reserves/GDP $t=150$ & 0.859 & 1.187 & -0.040 & 4.028 & 0.928 & 1.295 & -0.046 & 4.381 \\
\hline Reserves/GDP $t=300$ & 0.947 & 2.136 & -0.471 & 8.270 & 0.968 & 2.254 & -0.517 & 8.930 \\
\hline Balance/GDP $t=150$ & -0.001 & 0.005 & -0.007 & 0.004 & -0.002 & 0.006 & -0.008 & 0.004 \\
\hline Balance/GDP $t=300$ & 0.002 & 0.004 & -0.009 & 0.012 & 0.002 & 0.005 & -0.011 & 0.013 \\
\hline Average IRR (to year 300) & 0.019 & 0.006 & 0.002 & 0.030 & 0.019 & 0.006 & 0.002 & 0.030 \\
\hline \multicolumn{9}{|l|}{ Equation 3} \\
\hline Reserves/GDP $t=150$ & 1.381 & 0.196 & 1.057 & 1.841 & 1.548 & 0.280 & 1.102 & 2.176 \\
\hline Reserves/GDP $t=300$ & 1.057 & 0.460 & 0.498 & 1.851 & 1.203 & 0.533 & 0.572 & 2.266 \\
\hline Balance/GDP $t=150$ & 0.019 & 0.012 & -0.007 & 0.036 & 0.021 & 0.012 & -0.009 & 0.037 \\
\hline Balance/GDP $t=300$ & 0.008 & 0.008 & -0.008 & 0.021 & 0.008 & 0.009 & -0.009 & 0.025 \\
\hline Average IRR (to year 300) & 0.002 & 0.006 & -0.007 & 0.0164 & 0.014 & 0.007 & 0.003 & 0.0305 \\
\hline
\end{tabular}

Source: Authors' calculations. 
To better understand the interactions between the macroeconomy and the pension system under the Swedish and the proposed indexation mechanisms we simulated the effects of isolated changes in selected model variables on the steady-state levels of the fund reserves, cash balances, the path of the funding ratio and the IRR. The results are presented in Appendix 4. The main messages from the analysis can be summarized are follows.

First, it is interesting to observe that the Swedish system generates higher funding ratios than the proposal developed in this paper. This reflects the difference in the methodology used to calculate the pay-as-you-go asset. The new proposal implements a direct estimation of this asset. The Swedish system approximates this asset through the level of contributions and the turnover duration. The results suggest that this methodology tends to overestimate the pay-as-you-go asset.

Second, the new proposal generates more rapid adjustment paths in response to shocks. Fluctuations in adjustment paths are also less pronounced than in the case of the Swedish system. This is because the Swedish system is sensitive to changes in the growth rate of the covered average wage, which is in turn is very sensitive to economic shocks. The new proposal relies on the pay-as-you-go asset which dampens these fluctuations by also taking into account the effects on the dynamics of the population of contributors and beneficiaries.

Third, the Swedish system is very sensitive to changes in the growth rate of the population growth rate and there are cases where the system is not able to avoid negative reserve values. This can also be explained, in part, by a revalorization based on the growth rate of the covered average wage, which will be higher when population growth rates - and therefore the growth rate of the labor force - fall.

Finally, while the funding ratio falls when retirement probabilities, drop-out probabilities, and survival probabilities increase, the reduction is not always sufficient to activate the balancing mechanism. This implies that revalorization continues to depend on the growth rate of the covered average wage, while pensions are indexed by the growth rate of the average wage adjusted by the discount rate included in the annuity factor. When retirement probabilities increase, wages and the IRR go up. When survival probabilities increase, wages and the IRR go down. Only when the shock is driven by 
an increase in drop-out probabilities, which is less important for the dynamics of wages, at least in the short term, the IRR is more responsive to the funding level.

By looking at the IRRs generated by the Swedish system one can see that these are often above the IRRs generated by the new proposal, which as shown in the previous section, preserve the solvency of the system (i.e., liabilities are equal to assets).

The dynamics of the pension plan under the Swedish stabilization mechanism deserves further analysis. As previously discussed, the IRR paid by the system is roughly equal to the funding ratio times the growth rate of the average wage - when the balancing mechanism is on. The funding ratio in turn depends on the turnover duration that, when multiplied by total contributions, is supposed to provide an estimate of the assets of the plan - excluding the reserves. Because the turnover duration depends on average contributions and average pensions by age, it is sensitive to changes in retirement and dropout probabilities. It is also sensitive to changes in the age-wage profile and shocks that affect the marginal productivity of labor. Figure 5 displays the evolution of the turnover duration across the same 100 scenarios presented above. We observe that for several of the scenarios, those where macroeconomic, behavioral, and/or demographic shocks are observed, the TD is subject to important changes. These fluctuations, however, are often positive indicating a higher level of assets. Therefore, for several of the shocks assets would actually increase and the balancing mechanism would not be activated.

Figure 5: Dynamics of the Turnover Duration in the Swedish Stabilization System Annuity with discount factor

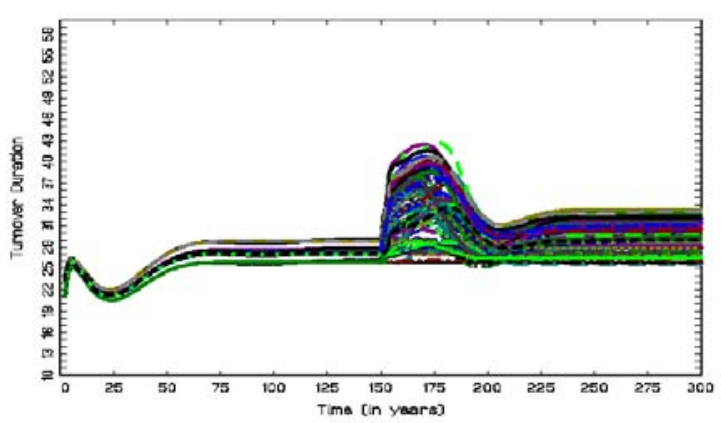
Annuity without discount factor Source: Authors' calculations.

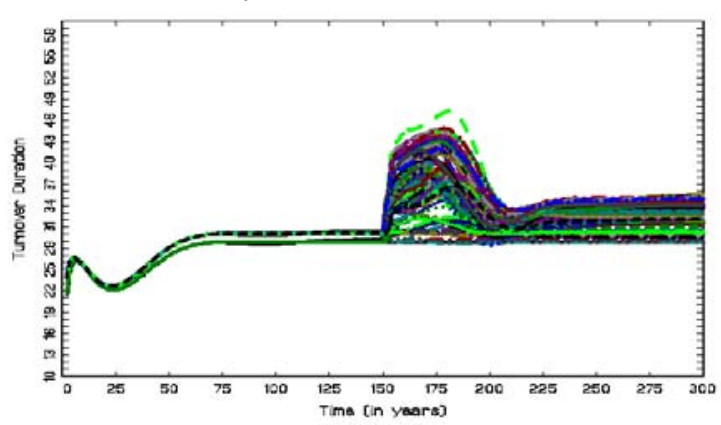




\section{Introducing Government Indexed Bonds}

The proposal to invest the contributions of the pension plan into government bonds to ensure financial sustainability and make pension liabilities explicit was, to our knowledge, first introduced by Buchanan (1968). Other theoretical discussions include (Auerbach and Kotlikoff, 1987; Sinn, 2000). There have also been proposals for applications of the concept (see Palacios and Sin, 2002) and Robalino et al. (2005a, 2005b), but the mechanics and fiscal implications have not been fully spelled out.

The idea is that, under the certainty case, a well designed ER system can be made financially self-sustainable if past wages (or contributions) and pensions are revalorized/indexed by the rate of return on the government bonds. Indeed, in this case, the value of the bonds held by the pension system is equal, at all points in time, to the pension liabilities. ${ }^{18}$ In addition, government bonds can serve other purposes: (i) improve fiscal management and provide incentives for a more careful choice of the parameters of the pension system -- since the liability is now explicit; (ii) facilitate the transparent financing of the IPD of a pre-existing system; and (iii) reduce the risk of capital loss if workers savings are managed by a public institution where governance, accountability and investment policies are week. If at some point in time the government bonds become tradable, then this policy can also facilitate the transition to a defined-contribution fully-funded pension system.

There are two problems with the original idea however. First, when there is uncertainty regarding the evolution of demographic parameters, pension liabilities can increase - for instance due to an unexpected increase in life expectancies - while the value of the bonds remains constant. This would generate a liability within the pension system that is not "funded." This miss-match would need to be corrected by adjusting pensions (retirees face the burden), by introducing a temporary contribution that does not accrue pension rights (a tax on labor), and/or general revenues (tax payers face the cost).

A second problem is that, as shown in Section 2, the sustainable IRR that the ER system can afford to pay on contributions (and can use to index pensions) could be

${ }^{18}$ The same caveat regarding the discount factor used in the calculation of the IPD and the indexation policy which were discussed above apply. 
above the growth rate of return on the bond, which is presumably below the rate of return of the market portfolio. This is because of the presence of the pay-as-you-go asset. By paying a rate of return below the sustainable rate, the share of bonds in GDP could increase too fast and plan members would be penalized.

The implication is that even if contributions are allocated to government bonds, it is desirable that the IRR of the system be calculated on the basis of equation (3) above.

In the remainder of this section we discuss how the proposed system could be designed, what are the considerations to keep in mind, and what would be the fiscal implications. In particular, we address the following questions: (i) what types of government bonds could be used; (ii) how the ratio of bonds to GDP would evolve; (iii) how bonds should be issued/repaid and what would be the proper accounting within the fund; and (iv) what would happen if the bonds are traded.

\section{Types of bonds}

In principle, any type of government bond could be used to invest the contributions of the ER system. The choice is both important from a fiscal point of view and from the perspective of the pension fund. For the latter, since different bonds have different yields, choices affect the IRR that the system pays and thus replacement rates for a given level of the contribution rate. We argue, however, that fiscal considerations should dominate in this case. First, because if the financial arrangement is not fiscally sustainable, then the pension system would not be either. Second, because investments in any type of bond are a premium relative to the pure pay-as-you-go system - where individuals are expected to earn only the rate of return on the pay-as-you-go asset.

Given the desire to keep the size of the government liability manageable in relation to government revenues - which are used to serve this liability - one natural alternative to consider is the issuance of GDP indexed government bonds. ${ }^{19}$ As

\footnotetext{
${ }^{19}$ Tax revenues indexed government bonds could be a variation, but one that could be very difficult to implement. Another alternative is a government bond with a coupon rate that would be identical to the sustainable internal rate of return of the pension system. Further research is needed to assess implementation issues, including impacts on government finances as a result of economic and-or demographic shocks. We conjecture, however, that IRR indexed bonds would behave similarly to GDPindexed bonds. The bond would be an interesting construct because, if traded, the market yield on the bond and the risk premium on other government obligations jointly would provide sufficient information to
} 
discussed in Borensztein and Mauro (2004) these bonds can protect the government against increases in interest rates that would raise debt/GDP ratios - in exchange for a relative small premium. Clearly, there are questions as to whether governments would have incentives to underreport GDP, or whether investors would be interested in the new financial instrument. Through the pension funds, however, plan members become a powerful constituency to motivate appropriate reporting. Moreover, by opening the market for this type of bond the pension fund could generate demonstration effects, creating demand for the instrument if it becomes tradable (see Borensztein and Mauro, 2004 for a discussion).

\section{Implementation and accounting}

How would bonds be issued and priced, and how would the pension fund manage the accounts? The idea is that every 6 or 12 months, the cash-surplus of the pension fund would be invested in GDP indexed government bonds (in the transition period cash balances could take the form of bank deposits). These bonds are similar to "plain vanilla" bonds except that the coupon rate is variable. It varies as a function of the growth rate of the economy. In the general form, the coupon rate would be defined by:

$$
r_{t}=\bar{r}+\Omega+\alpha\left(g_{t}-\bar{g}\right),
$$

where $r_{t}$ is the interest rate applied to pay the coupon of the bond at some time $t$ after the issuance of the bond, $\overline{r_{t}}$ is the coupon rate paid on pure vanilla bonds of identical maturity at the time of the issuance of the GDP-indexed bond, $\Omega$ is a premium that invertors could demand given more variance in the bond, $\alpha$ is the parameter of indexation, $g$ is the GDP growth rate at time $t$ and $\bar{g}$ is the GDP growth rate expected at the time of issuance. So the value of the coupon is calculated each year on the basis of the expected and observed growth rate of the economy.

By design pension liabilities are always backed by government bonds. This would imply that pensions are covered out of revenues from the bonds and that all new

determine whether the set of projections and probability distributions used in the calculation of the IRR is appropriate in the eyes of the market. In a way, the IRR indexed government bond could be a feasible way of using market forces to determine the expected IRR based on all the currently available information along the lines of Covered Wage Bill Bonds as discussed in Valdez-Prieto (2005a) and (2005b). 
contributions are invested in new bonds. In practice, of course, this does not have to be the case. The pension fund would invest in government bonds its operating balance (including revenues from coupon payments and bonds that mature). When the revenues from bonds that mature exceed pension payments - this can happen as the maturity rates of the bonds are not necessarily aligned with retirement patterns (are shorter in this case) -- the surplus is reinvested in new government bonds. On the other hand, if pension payments are above the value of bonds that mature - meaning that maturities were too long for retirement patterns, contributions can cover the difference. From the point of view of the pension fund, this operation is equivalent to having sold part of the bonds to cover the gap, while buying the equivalent amount of new bonds with the new contributions.

The accounting of the proposed system is simple. On the asset side of the balance sheet the pension fund keeps track of the pay-as-you-go asset and the stock of bonds - initially registered at face value since they are not traded. This stock moves as a function of the repayments and the balance of the fund. On the liability side of the balance sheet, the pension fund tracks separately the notional individual accounts (remunerated on the basis of equation 3) and the mathematical reserves for pensions in payment (indexed on the basis of equation 3).

When individuals retire the notional capital accumulated in their individual account is transferred to the mathematical reserves. Alternatively, if the system outsources the issuance of annuities, the lump sum capital would be transferred to the selected insurance company and subtracted from the IPD.

\section{Fiscal sustainability}

How would the bonds/GDP ratio ${ }^{20}$ evolve over time? The evolution of this ratio will depend on the growth rate of GDP, which affects the growth of the stock of bonds, as well as new issuances. New issuance will take place as long as contributions are higher than pensions. To see this, it is useful to write the cash flows that the government will require annually for serving bonds obligations. It is given by:

$$
F_{t}=B_{t-1} \varepsilon_{t-1}-\left[C_{t}+B_{t-1} \varepsilon_{t-1}-P_{t}\right]
$$

\footnotetext{
${ }^{20}$ We refer to the sum of the face value of the bonds divided by total GDP.
} 
where $B_{t-1}$ is the stock of bonds at year $t-1, \varepsilon_{t-1}$ the share of bonds that mature, $C_{t}$ are total contributions at time $t$, and $P_{t}$ are total pensions. The expression in brackets gives the net balance of the pension fund. We see that when contributions are higher than pensions, the government is not only rolling over payments, but also issuing new bonds. When contributions equal pensions, the government can just roll the bonds over. When contributions are below pensions, it is time for the government to start financing part of the bonds out of general revenues. This is important to emphasize. Bonds have to be repaid out of general revenues; the pay-as-you-go asset goes to the plan members, not to the government.

As such, the analysis of sustainability of GDP indexed government bonds linked to the pension system is no different from the analysis of sustainability of other forms of public debt. The only change is that the analysis needs to take into account the future cash-balance of the pension fund, which allows the government to roll-over the bonds.

So where to stop? When the new ER system replaces an ER system that had a large IPD and the government is cash-trapped, choices would be limited. New issuances of GDP indexed government bonds would be used to pay the pensions of the old-system, in effect making its implicit debt explicit. Above and beyond that level, however, the government does have several options.

One option is to allocate revenues from bond issuances to the repayment of other debt (with higher yields) or investments in liquid financial assets.

Another option, not mutually exclusive, is to reduce the level of borrowing by allowing the pension fund to diversify investments. Basically, part of the reserves would be allocated to a diversified portfolio of financial assets. This option can go hand in hand with the tradability of the government bonds. Clearly, before implementation the appropriate governance structure would need to be in place to ensure that funds are managed in the best interest of plan members.

In any event, rating agencies would need to monitor the public debt and penalize governments where GDP indexed bonds linked to the pension system start to accumulate well beyond the level of implicit debt of the old-system, without reductions in other sources of government debt. The idea is for the new instrument to be an alternative source of financing rather than an additional source of financing. 
To illustrate the potential fiscal impact of linking the contributions of an ER system to government indexed bonds, we simulate the net balance of the pension fund -which as shown above is equivalent to the amount of general revenues necessary to repay bonds at a given point in time -- under another set of economic and demographic scenarios. Since in our model GDP growth is exogenous and not subject to stochastic shocks, we use a simple type of bonds where $r=0, \Omega=0, \alpha=1$, and $\bar{g}=r$. So, the coupon rate is exactly equal to GDP growth. We implement the simulations in the case of two designs: (i) the IRR takes into account the pay-as-you-go asset (equation 3); (ii) the IRR does not take into account the pay-as-you-go asset (simple indexation by GDP growth). The results are presented in Figure 6.

A first observation is that the system with stabilization mechanism generates lower deficits and lower, but always positive, steady state bonds to GDP ratios - which is presumably good to control the accumulation of government debt. In essence, the government would have less room for borrowing.

The second observation is that all systems can generate negative cash-balances. The size of the short-fall between contributions and benefits depends on the nature of the underlying shocks. In most cases, the short-falls should be covered by the value of the coupons and the bonds that mature. In some cases, as a result of a large unexpected shock, short falls can be large. In the scenarios that we have considered, which as said before, set very high standards for the pension fund, the deficit in the case of the system with a stabilization mechanism could be as large as 7\% to $8 \%$ of GDP. Clearly, dealing with large shocks is a challenge for any pension system. In this case there are also various ways to proceed. One is for the pension fund to request advance payment of part of the stock of bonds. If the government faces liquidity constraints and/or was affected by the same shock that hit the pension fund, it could borrow without changing the fiscal stance -- it would replace one type of debt by another. The other possibility is for the pension fund to trade government bonds. This option of course has implications for the value of the bonds and deserves a separate discussion. 
Figure 6: Fiscal Impact of GDP Indexed Bonds With and Without Stabilization Mechanism Pure GDP Indexation
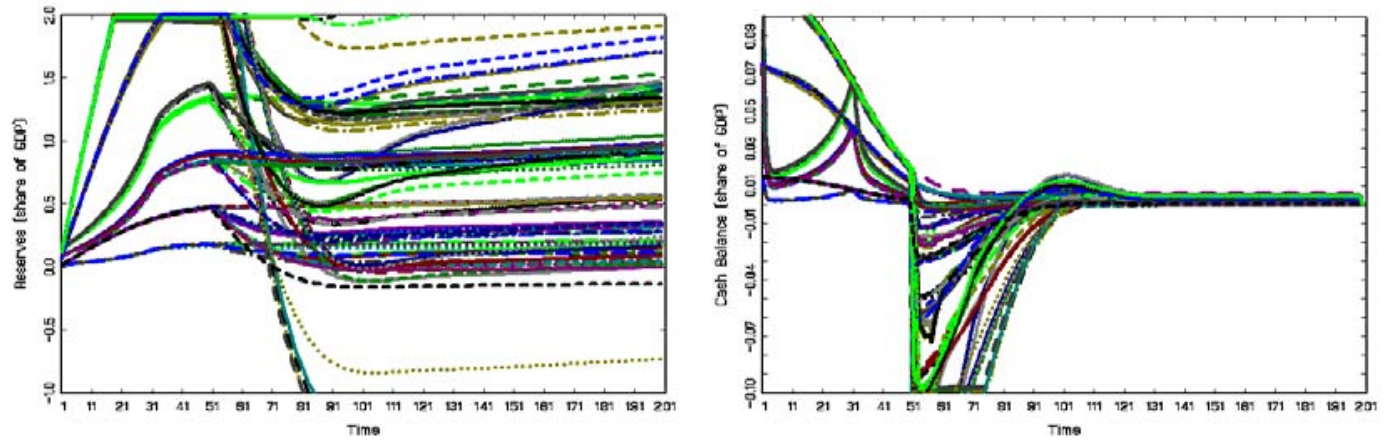

GDP Indexation Plus Stabilization Mechanism
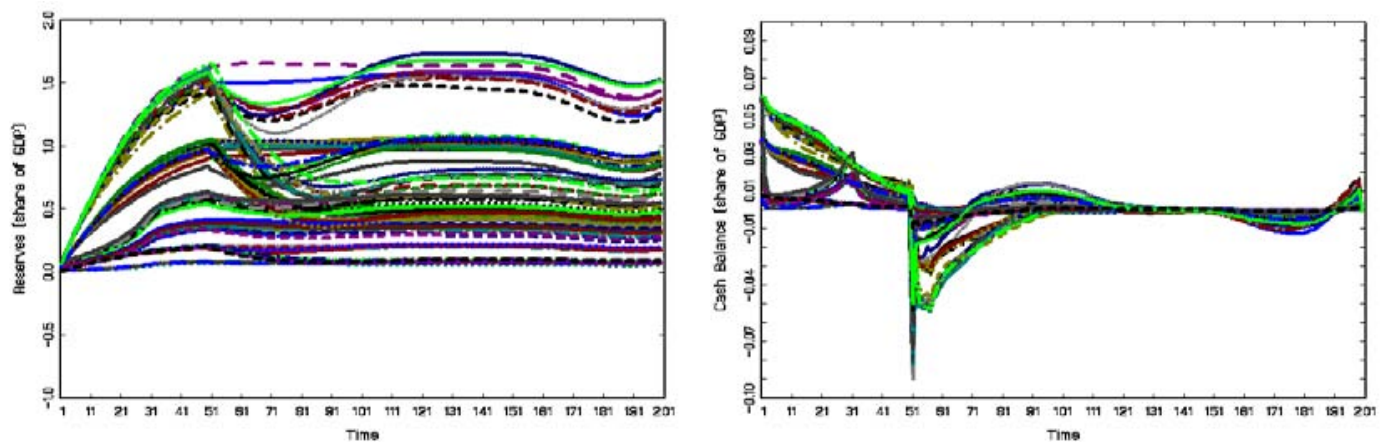

Source: Authors' calculations

What happens when the GDP bonds owned by the pension fund are traded? In the unlikely case that the yield demanded by investors was exactly equal to the coupon rate, nothing would happen. The market price of the bonds would be equal to the face value of the bonds. In reality things are different. Investors will hold GDP indexed government bonds as long as these generate a premium that is "worth" the risk; not only the risk embedded in the variable coupon (which depends on GDP growth), but also the country risk, the risk of default by the government, and the liquidity risk that accompanies a market that has not yet developed. Country risk and risk of default are already captured by standard government bonds. The question is what the extra premium to accept the extra risk is. Under certain assumptions regarding the behavior of investors, this premium would be a function of the expected rate of return on a risk free asset, the expected growth rate of GDP, and the covariance of this growth rate with the "market portfolio." Bottom line, the higher the country risk, the higher the perceived probability of default, the lower the expected growth rate of the economy, and the higher the covariance between the growth rate of GDP and the market portfolio, the 
higher the premium requested from investors (the higher $\Omega$ ). The higher the premium, the lower the price they are willing to pay for the government bonds. Hence, it can be the case that when the pension system trades the government bonds it also abruptly loses the value of the assets. This is particularly true at times of crisis, but it can happen in normal times as well, simply because when the government issues the bonds it is not paying the risk premium that markets would have demanded $(\Omega=0)$. One possibility to solve this problem is to trade a portion of the bonds from the beginning or, even better, to have a parallel issuance from the start. In this way the pension fund will also have a benchmark to price the bonds.

\section{Discussions and Policy Implications}

In this paper we have proposed a mechanism to design a financially sustainable and secure earnings related scheme with pay-as-you-go financing. The mechanism combines the investment of reserves in GDP indexed government bonds with a new measure for the rate that the plan should use to revalorize contributions and index pensions (i.e., the sustainable implicit rate of return on contributions). This rate is a function of the growth rate of the reserves (in this case the stock of government bonds) and the so called pay-as-you-go asset of the system.

We argue that the proposed approach has several virtues: (i) it eliminates the risk of mismanagement of the funds that inevitably accumulate during the first couple of decades, and which are necessary to finance pensions when the system matures; (ii) it improves fiscal management by making the implicit liabilities of the new system explicit; (iii) it provides incentives and controls for policymakers to respect rules that ensure the long-term financial sustainability of the ER system; (iv) it facilitates the transition to the "new" system in countries where the "old" ER system has accumulated a large IPD; and (v) facilitates the transition to a defined-contribution funded scheme.

While the proposed arrangements could serve any ER system, they are better suited for notional account systems that establish a clear link between contributions, the rate of return on these contributions, and pensions. In addition, this system has a simple characterization of the IPD: the sum of notional capital in the individual accounts, plus pensions in payment by age cohort times the annuity factor of that cohort. 
There are, however, issues that could affect implementation and that deserve further attention. A first set of issues has to do with the mechanism used to compute the IRR on contributions. One is that the value of the pay-as-you-go asset will depend on expectations about the initial IRR and the growth rate of wages - this could give room to discretion. The second is that financial sustainability requires that in some circumstances the IRR be negative. Since this rate is used to index pensions the approach would require that individuals accept the possibility of having their pensions drop in absolute terms. This is unlikely to be appealing to individuals. One way around this is to have pension which are only indexed by inflation but that in the calculation include an implicit interest rate. The stabilization mechanism suggested here would then ensure that the IRR paid on contributions is properly adjusted.

Another question is the level of sophistication of the scheme. Some might consider that the proposed method to compute the IRR is complex and that pensions systems in middle and low income countries will not have the institutional capacity to implement. Our position is that creating this institutional capacity should be part of any reform program -- including one that intends to keep defined benefit provisions intact. In all cases, information and administrative systems should be upgraded to ensure that the pension fund can properly track the contributions of plan members and other individual characteristics. In all cases the managers of the pension plan should have access to up to date financial information including the evaluation of the liabilities of the plan.

A third set of issues has to do with fiscal implications. In the paper we argue that the fact that the government mandates a pension scheme that is not fully funded automatically creates an implicit liability. The proposed arrangement does not change the nature of that liability - it simply makes it explicit. Furthermore, because the bonds are a debt of the government with a public institution they cancel out in the reporting of the consolidated public debt. ${ }^{21}$ This being said, the analysis of sustainability of the public debt should take into account the accumulation of GDP indexed bonds with the pension fund. This is simply because, as shown in the paper, the sustainability of the pension plan does depend on the ability of the government to serve the bonds. So, the

\footnotetext{
${ }^{21}$ This is in fact problematic since in this case the liability of the pension fund with plan members should be considered part of the consolidated public debt.
} 
existence of these bonds imposes constraints on the use of other forms of financing. Because the bonds are linked to GDP and at least initially do not require a premium, they actually could be a very interesting source of financing for the public sector. Still, there are several questions that require further analysis. For instance, how would the existence of the bonds change the structure of the public debt and the spreads on other bonds? How does the cost of the indexed bonds compare to other debt instruments? Will the government be able to meet the demand for bonds? How will investors react to the accumulation of GDP indexed bonds? When should the bonds be allowed to be traded? These are important questions that fall outside the scope of the paper and that should be considered in future research.

\section{References:}

Auerbach, Alan J. and Laurence J. Kotlikoff. 1987. Dynamic Fiscal Policy, Cambridge University Press.

Buchanan, James M. 1968. "Social insurance in a growing economy: a proposal for radical reform." National Tax Journal, 21, December, 386-39.

Holzmann, Robert, and Edward Palmer, eds. 2006. "Pension Reform: Issues and Prospects for Non-Financial Defined Contribution (NDC) Schemes." Washington, DC: World Bank.

Holzmann, Robert, Robert Palacios, and Asta Zviniene. 2001. “On the Economics and Scope of Implicit Pension Debt: An International Perspective.” Empirica, 28, pp. 97-129.

Lindeman, David, David Robalino, and Michal Rutkowski. 2006. “NDC Pension Schemes in Middle- and Low-Income Countries." In Robert Holzmann and Edward Palmer, eds., Pension Reform: Issues and Prospect for Non-Financial Defined Contribution (NDC) Schemes. Washington, D.C.: World Bank.

Palacios, Robert and Yvonne Sin. 2002. "Pension Policy Options in Eritrea." Report No. 28541-ER, Poverty Reduction and Economic Management 2, Country Department 5, Africa Region. Washington, DC: World Bank.

Robalino, David, Edward Whitehouse, Anca Mataoanu, Alberto Musalem, Elisabeth Sherwood, Oleksiy Sluchinsky. (2005). Pensions in the Middle East and North Africa Region: Time for Change. World Bank. Washington DC.

Robalino, David, and Tatyana, Bogomolova. (forthcoming). "Implicit Pension Debt in the Middle East and North Africa: Magnitude and Fiscal Implications." Washington, DC: World Bank. 
Robalino, David, Richard Hinz, Oleksiy Sluchinsky, Mark Dorfman, and Anca Mataoanu. 2005. "Egypt: A Framework for an Integrated Reform of the Pension System." Unpublished Report. World Bank. Washington DC.

Settergren, Ole. 2001. "The Automatic Balance Mechanism of the Swedish Pension System - A Non-technical Introduction." Stockholm: Swedish National Social Insurance Board.

Settergren, Ole. ed. 2005. “The Swedish Pension System Annual Report.” Stockholm: Swedish Social Insurance Agency.

Settergren, Ole, and Boguslaw Mikula. 2005. "The Rate of Return of Pay-as-You-Go Pension Systems." In Robert Holzmann and Edward Palmer, eds., Pension Reform: Issues and Prospect for Non-Financial Defined Contribution (NDC) Schemes. Washington, D.C.: World Bank.

Valdéz-Prieto, Salvador. 2005a. "Pay-as-you-go securities." Economic Policy, 42, April, p. 215-251, London (CEPR).

Valdés-Prieto, Salvador. 2005b. "A Market-based Social Security without Transaction Cost." Unpublished manuscript. Catholic University of Chile, Santiago.

Sinn, H.W. (2000) "Why a funded pension is useful and why it is not", International Tax and Public Finance 7, p. 389-410, also CESifo Working Paper № 195, September 1999. 


\section{Appendix 1}

Derivation of $P(b)$ the average pension of all individuals in a cohort retired by age $b$

The average virtual capital accumulated by an individual of a cohort $a$ at time $t$ who retires at age $i$ with $i \leq b$ :

$C(a)_{t}+\beta W_{t} \int_{j=a}^{i} e^{g(j-a)} w(j) e^{r^{*}(i-j)} d j$

If we turn this virtual pension capital into an annuity, the average pension payment of an individual of cohort $a$ retiring at age $i$ with $i \leq b$ in the period when the individual reaches age $b$ (i.e. at time $t+b-i$ ) is as follows:

$$
\left\{C(a)_{t}+\beta W_{t} \int_{j=a}^{i} e^{g(j-a)} w(j) e^{r^{*}(i-j)} d j\right\} G\left(i, l(.), r^{*}\right) e^{r^{*}(b-i)}
$$

Recall that $R(b)$ is the share of the age cohort (any age cohort given constant retirement probabilities) that retired by age $b$. Consequently $[R(i)-R(i-1)] / R(b)$ is the share of $R(b)$ that is associated with those who retired between ages $i-1$ and age $i$. Consequently the formula for the average pension payment at time $t$, calculated in relation to all individuals in age cohort $a$ who retire at or before age $b$, can be constructed by integrating the previous formula over all retirement ages between $a$ and $b$ and including relative weights of the population retired between ages $i$ and $i-1$ :

$$
P(b, a)=\int_{i=a}^{b}\left\{C(a)_{t}+\beta W_{t} \int_{j=a}^{i} e^{g(j-a)} w(j) e^{r^{*}(i-j)} d j\right\} G\left(i, l(.), r^{*}\right) e^{r^{*}(b-i)}\left(\frac{R(i)-R(i-1)}{R(b)}\right) d i .
$$

Derivation of $Z(i, t)$, the $Z$ factor

The present value of future contributions assuming that that age profile of wages function $w($.$) is consistent with the average growth rate of the covered wage bill g$ on the individual level is as follows:

$W_{t} w(i) \beta \sum_{a=i}^{L} \frac{l(a) v(a) d(a)}{l(i) v(i) d(i)}\left(\frac{1+g}{1+\rho}\right)^{a-i}$. 
The joint probability that an active person of age $a$ either retires or drops out by age $a+1$ is $[1-v(a+1) / v(a)]+[1-d(a+1) / d(a)]$. Assuming that the virtual pension capital to be accumulated beyond age $i$ is to be used to purchase an annuity at retirement/drop-out age $a$, the present value of pension benefits to be earned through future contributions by age cohort $i$ is as follows:

$W_{t} w(i) \beta \sum_{a=i}^{L} \frac{l(a) v(a) d(a)}{l(i) v(i) d(i)}\left[\left(1-\frac{v(a+1)}{v(a)}\right)+\left(1-\frac{d(a+1)}{d(a)}\right)\right] \frac{1}{(1+\rho)^{a-i}} \sum_{j=i}^{a}(1+g)^{j-i}\left(1+E\left[r^{*}\right]\right)^{a-j}$.

Based on (A1-4) and (A1-5) and applying the sum of geometric series formula we have that

$Z(i, t)=W_{t} W(i) \beta \sum_{a=i}^{L}\left\{l\left(\frac{l(a) v(a) d(a)}{l(i) v(i) d(i)}(\underbrace{\left(\frac{1+g}{1+\rho}\right)^{(a-i)}}_{A}-\underbrace{\frac{1}{(1+\rho)^{a-i}} \frac{\left.1+E\left(r^{*}\right)\right]^{a}}{(1+g)^{i}}\left[\frac{\left(\frac{1+g}{1+E\left(r^{*}\right)}\right)^{i}-\left(\frac{1+g}{1+E\left(r^{*}\right)}\right)^{a+1}}{1-\left(\frac{1+g}{1+E\left(r^{*}\right)}\right)}\right]\left(\left(1-\frac{v(a+1)}{v(a)}\right)+\left(1-\frac{d(a+1)}{d(a)}\right)\right)}_{B}] .(\right.\right.$ A $1-6)$ 


\section{Appendix 2}

Welfare implications of the indexation mechanism of pensions

What are the welfare implications of offering a pension that is constant in real terms (annuity includes the IRR in the calculation) or a pension that can grow in real terms (IRR is not included in the calculation of the annuity). The answer depends on what we believe about the preferences, the "patience" and the rationality of participants of the pension scheme. For the purposes of this analysis we make the standard assumptions that the preferences of agents can be represented by a concave utility function over consumption and that the economy is in a long-term equilibrium (including demographic considerations) such that the growth rate of the economy, the return on risk-free assets and the IRR of the pension system are identical $(r)$ and constant. ${ }^{22}$ Under these assumptions the cash-flow structure of the NA pension system is irrelevant if agents can borrow and lend at a rate $r$. The interesting question emerges when this is not the case (i.e., they do not lend or borrow, but consume in the amount of their (pension) income every period). This is clearly not an assumption that holds in general, but extreme borrowing constraints imposed on low-income workers and the hiatus of a truly low-risk saving instrument for risk-averse agents may be features of reality, especially in low-income countries. For simplicity we also assume that all the wealth of the individual at the time of retirement is in the mandatory pension fund.

For the sake of simplicity we assume that individuals retire at age $R$ and live until age $R+T$, i.e. at the moment of retirement they have $T$ time units left of their life. The following equation determines the constant real value pension amount $p_{F}$ of an individual who had accumulated pension wealth $P W$ by retirement age $R$ :

$$
P W=p_{R} \int_{0}^{T} e^{-r t} d t=p_{R} \frac{\left(1-e^{-r T}\right)}{r}
$$

\footnotetext{
${ }^{22}$ The latter assumption is not crucial for the analysis, however, it allows us to disregard those outcomes of the model that are driven by the differences among the IRR of the pension system, the discount rate and the real return on the risk-free asset.
} 
For the initial real pension amount $\hat{p}_{F}$ that the same individual received under the pension cash-flow structure that provides for a growth of the real pension at rate $r$ the following equation would hold:

$$
P W=\int_{0}^{T} e^{-r t} \hat{p}_{R} e^{r t} d t=\hat{p}_{R} T
$$

Consequently the relationship between the two initial pension amounts is as follows:

$$
\hat{p}_{R}=p_{R} \frac{1-e^{-r T}}{r T}
$$

Claim: In a notional account pension system, under the model assumptions of Appendix 2, the pension cash-flow structure with constant real value pension payments provides strictly higher welfare for myopic agents than a financially neutral alternative cash-flow structure with constant growth of the pension amount at rate $r$.

Proof:

The agent with no access to financial markets enjoys the same earnings flow and consequent utility of full consumption of her/his earning during the active life period under both pension benefit calculation scenarios so the assessment of welfare implications can be limited to the consumption patterns beyond retirement.

The discounted total utility of the agent (restricted to the retired period) under the constant real value pension cash-flow structure is as follows when preferences are represented by utility functions $u\left(\right.$.) with $u^{\prime}($. $)>0$ and $u^{\prime \prime}($.) $<0$ :

$V\left(p_{F}\right)=\int_{0}^{T} e^{-r t} u\left(p_{F}\right)=\frac{1-e^{-r T}}{r} u\left(p_{F}\right)$

The discounted total utility of the agent under the pension cash-flow with real growth of pensions at rate $\mathrm{r}$ is as follows:

$$
\hat{V}\left(\hat{p}_{F}\right)=\int_{0}^{T} e^{-r t} u\left(e^{r t} \hat{p}_{F}\right)=\int_{0}^{T} e^{-r t} u\left(e^{r t} p_{R} \frac{1-e^{-r T}}{r T}\right) d t
$$


By concavity of $u($.$) we have:$

$$
\hat{V}\left(\hat{p}_{F}\right)=\int_{0}^{T} e^{-r t} u\left(e^{r t} p_{R} \frac{1-e^{-r T}}{r T}\right) d t<\int_{0}^{T} u\left(p_{R} \frac{1-e^{-r T}}{r T}\right) d t=T u\left(p_{R} \frac{1-e^{-r T}}{r T}\right)
$$

Consequently and by repeated application of the concavity of $u($.$) we have$

$\hat{V}\left(\hat{p}_{F}\right)<T u\left(p_{R} \frac{1-e^{-r T}}{r T}\right)<T \frac{1-e^{-r T}}{r T} u\left(p_{R}\right)=\frac{1-e^{-r T}}{r} u\left(p_{R}\right)=V\left(p_{R}\right)$

if $0<\frac{1-e^{-r T}}{r T}<1$; however, this is condition is easily satisfied since it means nothing else, but that $\hat{p}_{F}<p_{F}$, which holds in accordance with (A2-3).

This completes the proof. 


\section{Appendix 3}

\section{The Macro Model}

The formal description of the model is presented in Box A3-1. The various equations are organized in five blocks: population; labor force; output, wages and interest rates; plan members; and revenues and expenditures of the pension system. We briefly discuss each of these blocks.

The first two equations define the dynamics of the population $(N)$. Basically, the population of new born is assumed to grow at an exogenously defined rate $(\lambda)$. Given survival probabilities by age, the total number of individuals in each age cohort is computed at each point in time.

Equations (A3-3) and (A3-4) determine the evolution of the labor force $(L)$ and human capital $(H)$ respectively. The labor force is made of all individual of age $a \geq f$ (where $f$ is the minimum age to be considered economically active) and who have not retired. Thus, in equation (A3-3), $v(a)$ is the probability of not being retired by age $a$. The implicit assumption is that participation rates are $100 \%$ for all ages. This simplification does not affect the results from the analysis. As for human capital, it is defined as the sum of the labor force by age-cohort multiplied by their productivity/quality, which will affect the level of wages by cohort. Thus, in equation (A3-4), $\varepsilon(a)$ captures the age-wage profile.

Equations (A3-5) to (A3-11) determine output $(Q)$, the savings rate of the economy $(s)$, capital $(K)$, total factor productivity $(A)$, wages by age $(w(a))$, and the market interest rate $r^{m}$. The underlying assumption is that output is generated by a Cobb-Douglas function that incorporates human capital, physical capital, and total factor productivity. The growth rate of output $(g)$ is defined exogenously. The savings rate of the economy is defined in a way that, in the steady state, the level of capital ensures that the market interest rate (the marginal productivity of capital) equals $g \tau$, where $\tau$ is defined exogenously. This last parameter is basically the ratio between the real market interest rate and the growth rate of GDP. So, $(1-\alpha) /(g \tau)$ is the capital output ratio. Wages (by age) and the market interest rate are then computed under the 
assumption of full employment as the marginal productivity of labor (by age) and capital respectively. In equations (A3-6) to (A3-11), $\alpha$ is the share of human capital in production.

The evolution of the stocks of contributors $(C)$, dormants $(D$; individuals who stopped contributing but have pension rights), and old-age pensioners $(O)$ are given by equations (A3-12) to (A3-14). We assume that all individuals in the labor force join the pension system at the beginning of the simulation $(C(a, 1)=L(a, 1))$ and that all new entrants to the labor force join the pension system at time $t>1(C(f, t)=L(f, t))$. From there the stock of contributors, dormants, and old-age retirees respond to survival probabilities $l($.$) , dropping out probabilities d($.$) , reentry probabilities b($.$) , and the$ probability of continuing in the labor force instead of retiring $v(a)$. Notice that individuals who drop out of the pension system, do not drop out of the labor force. In this model, these individuals continue working and earning a salary - they simply do not contribute.

Finally, equations (A3-15), (A3-16), and (A3-17) give the dynamics of the capital value of the individual accounts and total pension expenditures for each age cohort, as the total reserves of the system. The new symbols in these two equations are: $r^{*}$, the revalorization/indexation factor for wages/pensions (i.e., the internal rate of return on contributions); $\beta$, the contribution rate; $G(a, t, i)$ the annuity factor at age and time, that depends on the interest rate $i$ (a policy parameter); and $\eta$ which gives the rate of return on investments of the reserves relative to the market interest rate.

The notional capital value of pension accumulation over a period for a given age cohort incorporates the previously accumulated capital and its returns plus current contributions of the surviving and not yet retiring portion of the given age cohort. Equation (A3-15) takes into account that contributions are paid continuously throughout the year. The total pension amount paid to an age cohort evolves from period to period in accordance with (A3-16). The surviving portion of previously retired individuals of the cohort will receive pensions indexed by the IRR and the accumulated pension capital of new retirees is turned into annuities. The reserves of the pension system (A3-17) evolve over time in accordance with the returns/borrowing costs on the previously available reserves and the sum of the balances of current contributions and "newly 
exchanged" pension annuities for all age cohorts. These balances are augmented by the investment returns/ borrowing costs assessed on their continuous flows during the applicable year. 


\section{Box A3-1: Model for Analysis of Robustness of Rules on IRRs}

Initial and total population by age-cohort:

$N(0, t)=N(0,1)(1+\lambda)^{t-1}$,

$N(a, t)=\frac{N(0, t)}{(1+\lambda)^{a}} l(a)$

Labor force by age cohort and human capital:

$L(a+1, t+1)=L(a, t) \frac{l(a+1)}{l(a)} \frac{v(a+1)}{v(a)} ; \quad L(a, 1)=N(a, 1) \quad \forall a \geq f ; \quad L(f, t)=N(f, t)$,

$H(t)=\sum_{a=f}^{M} \varepsilon(a) L(a, t) ;$

Output, productivity, wages and interest rate:

$$
\begin{aligned}
& Q(t)=Q(1)(1+g)^{t-1} \\
& Q(t)=A(t) H(t)^{\alpha} K(t)^{1-\alpha} \\
& s=\frac{(1-\alpha)}{g \tau} g=\frac{1-\alpha}{\tau} \\
& K(t)=K(t-1)+s Q(t-1) ; \quad K(1)=\frac{(1-\alpha)}{g \tau} Q(1) \\
& A(t)=Q(t) H(t)^{-\alpha} K(t)^{\alpha-1}, \quad \\
& w(a, t)=\alpha A(t) H(t)^{\alpha-1} K(t)^{1-\alpha} \varepsilon(a), \\
& r^{m}(t)=(1-\alpha) A(t) H(t)^{\alpha} K(t)^{-\alpha}=(1-\alpha) \frac{Q(t)}{K(t)}
\end{aligned}
$$

Contributors, dormants, and old-age pensioners:

$$
\begin{aligned}
& C(a+1, t+1)=\left[C(a, t) \frac{l(a+1)}{l(a)}\right]\left[\left(-d(a)+\frac{v(a+1)}{v(a)}\right)\right]+D(a, t) \frac{l(a+1)}{l(a)} b(a) ; C(a, 1)=L(a, 1), C(f, t)=L(f, t) \\
& D(a+1, t+1)=D(a, t) \frac{l(a+1)}{l(a)}(1-b(a))+C(a, t) \frac{l(a+1)}{l(a)} d(a) \\
& O(a+1, t+1)=O(a, t) \frac{l(a+1)}{l(a)}+[C(a, t)+D(a, t)] \frac{l(a+1)}{l(a)}\left(1-\frac{v(a+1)}{v(a)}\right)
\end{aligned}
$$

Individual accounts by age cohort, total pensions by age-cohort, and total reserves:

$$
\begin{aligned}
& I(a+1, t+1)=\left[I(a, t)\left(1+r^{*}(t)\right)+C(a, t) w(a, t) \beta\left(1+\frac{r^{*}(t)}{2}\right)\right] *\left[1-\frac{l(a+1)}{l(a)}\left(1-\frac{v(a+1)}{v(a)}\right)\right] \\
& P(a+1, t+1)=P(a, t)\left(1+r^{*}(t)\right) \frac{l(a+1)}{l(a)}+\frac{I(a, t)\left(1+r^{*}(t)\right) \frac{l(a+1)}{l(a)}\left(1-\frac{v(a+1)}{v(a)}\right)}{G(a+1, t+1, i)}, \\
& R(t)=R(t-1)\left(1+\eta r^{m}(t)\right)+\sum_{a=f}^{M}\left[C(a, t) w(a, t) \beta-\frac{I(a, t)(1+r) \frac{l(a+1)}{l(a)}\left(1-\frac{v(a+1)}{v(a)}\right)}{G(a+1, t+1, i)}\right]\left(1+\frac{\eta r^{m}(t)}{2}\right)
\end{aligned}
$$




\section{Appendix 4}

The following figures compare the sensitivity/robustness of the Swedish automatic balance mechanism and that of the indexation mechanism of the proposal developed in this paper towards certain demographic shocks holding all other factors constant. The baseline simulation path scenario corresponds to state 1 in Table 1 . The deviating paths are identified in the figure legends and they correspond to the alternative states defined in Table 1 . The sensitivity analysis towards population growth and survival patterns include one additional path each. All the simulations here apply annuity calculations with discounting. 
Sensitivity Analysis - Population Growth Scenarios

Evolution of the Reserves and Balance of the Pension System as a Share of the GDP, the Funding Ratio and Dynamic Internal Rate of Return of the Pension System under the Swedish Automatic Balance Mechanism and the New Indexation Proposal

Swedish automatic balance mechanism
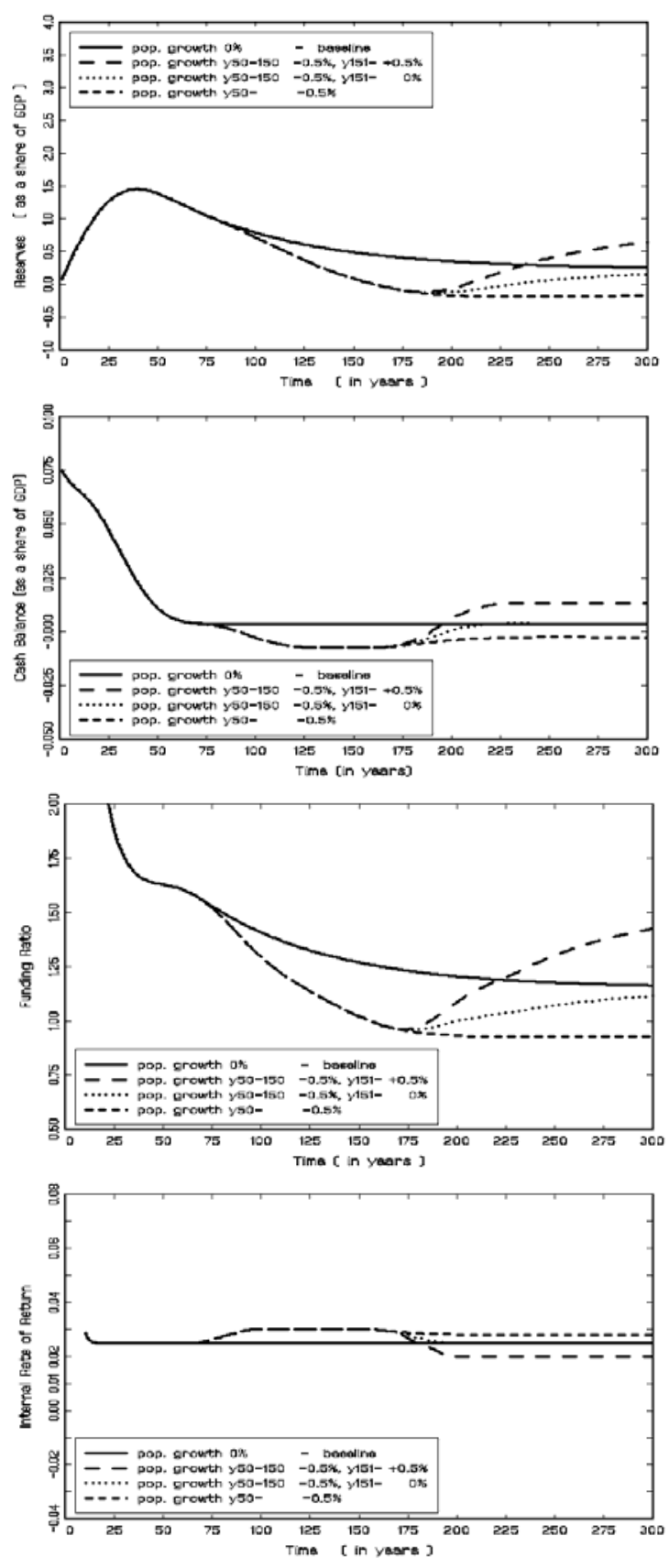

new proposal
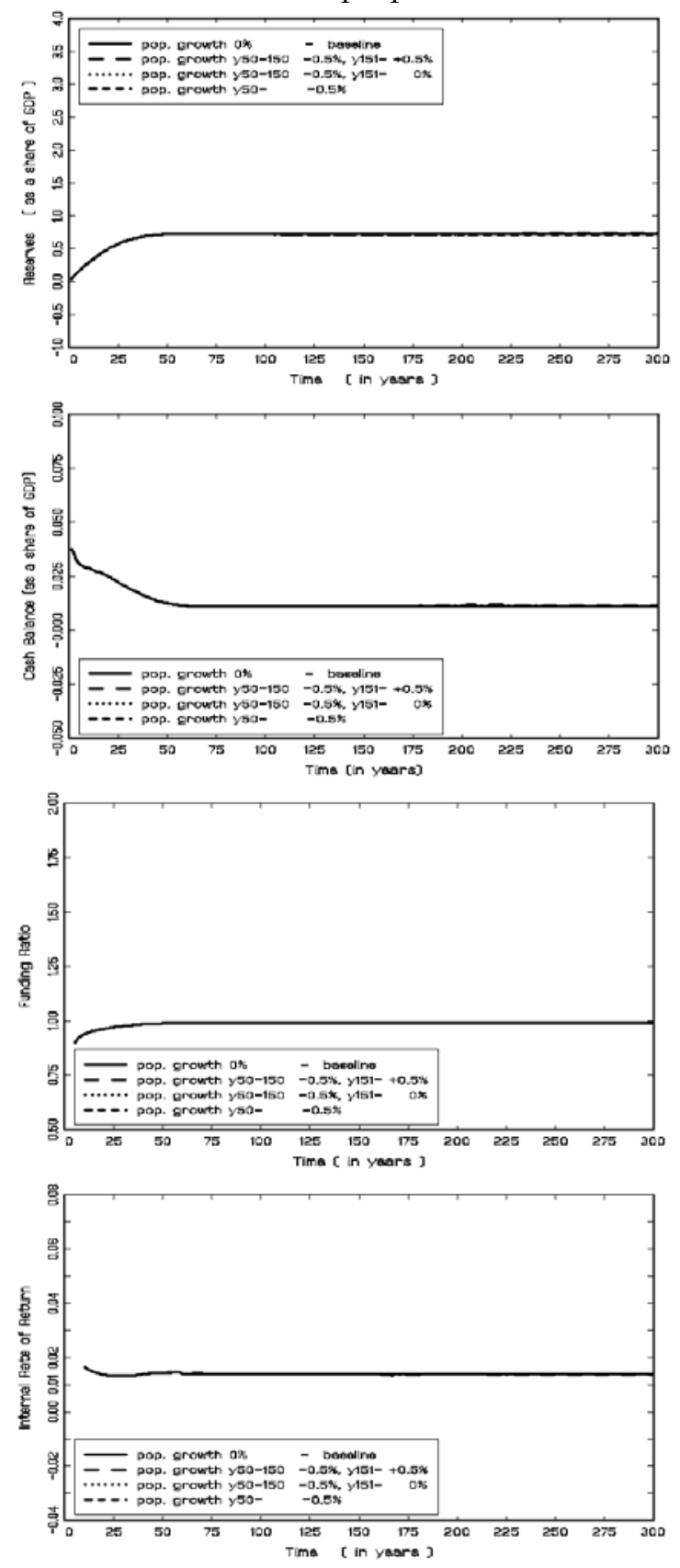
Sensitivity Analysis - Survival Pattern Scenarios

Evolution of the Reserves and Balance of the Pension System as a Share of the GDP, the Funding Ratio and Dynamic Internal Rate of Return of the Pension System under the Swedish Automatic Balance Mechanism and the New Indexation Proposal

Swedish automatic balance mechanism

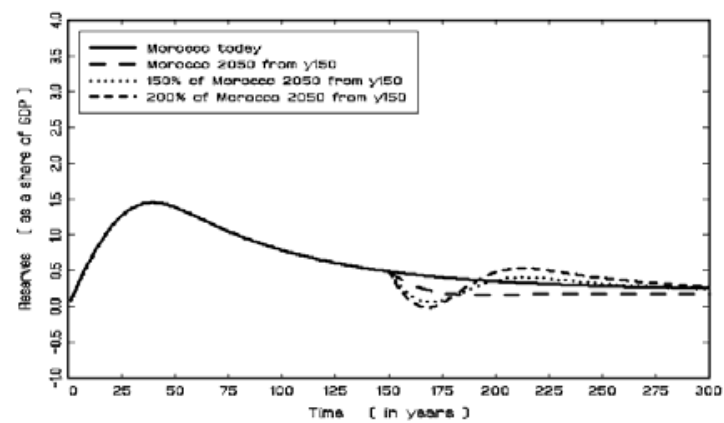

new proposal
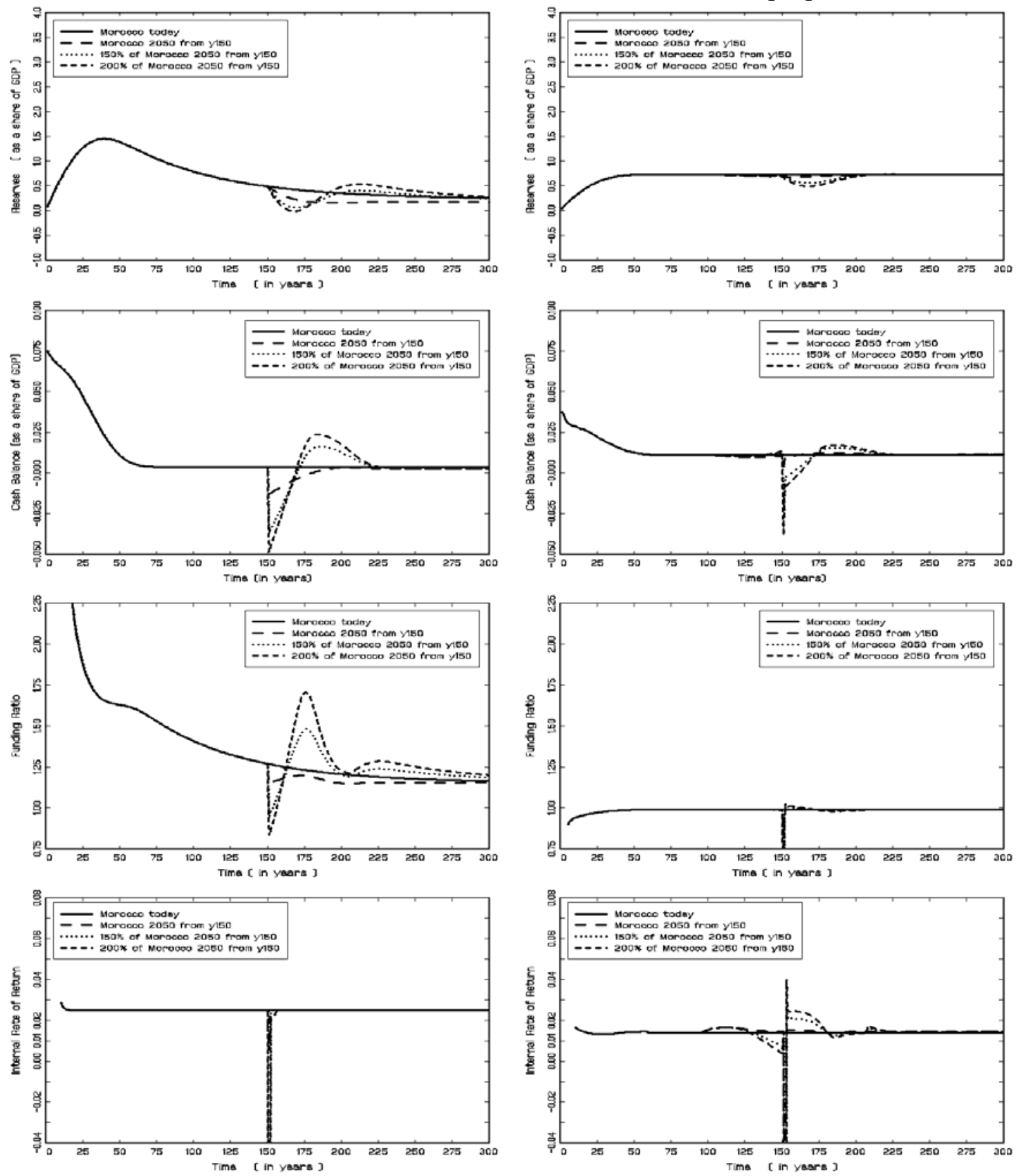
Sensitivity Analysis - Retirement Probability Scenarios

Evolution of the Reserves and Balance of the Pension System as a Share of the GDP, the Funding Ratio and Dynamic Internal Rate of Return of the Pension System under the Swedish Automatic Balance Mechanism and the New Indexation Proposal

Swedish automatic balance mechanism
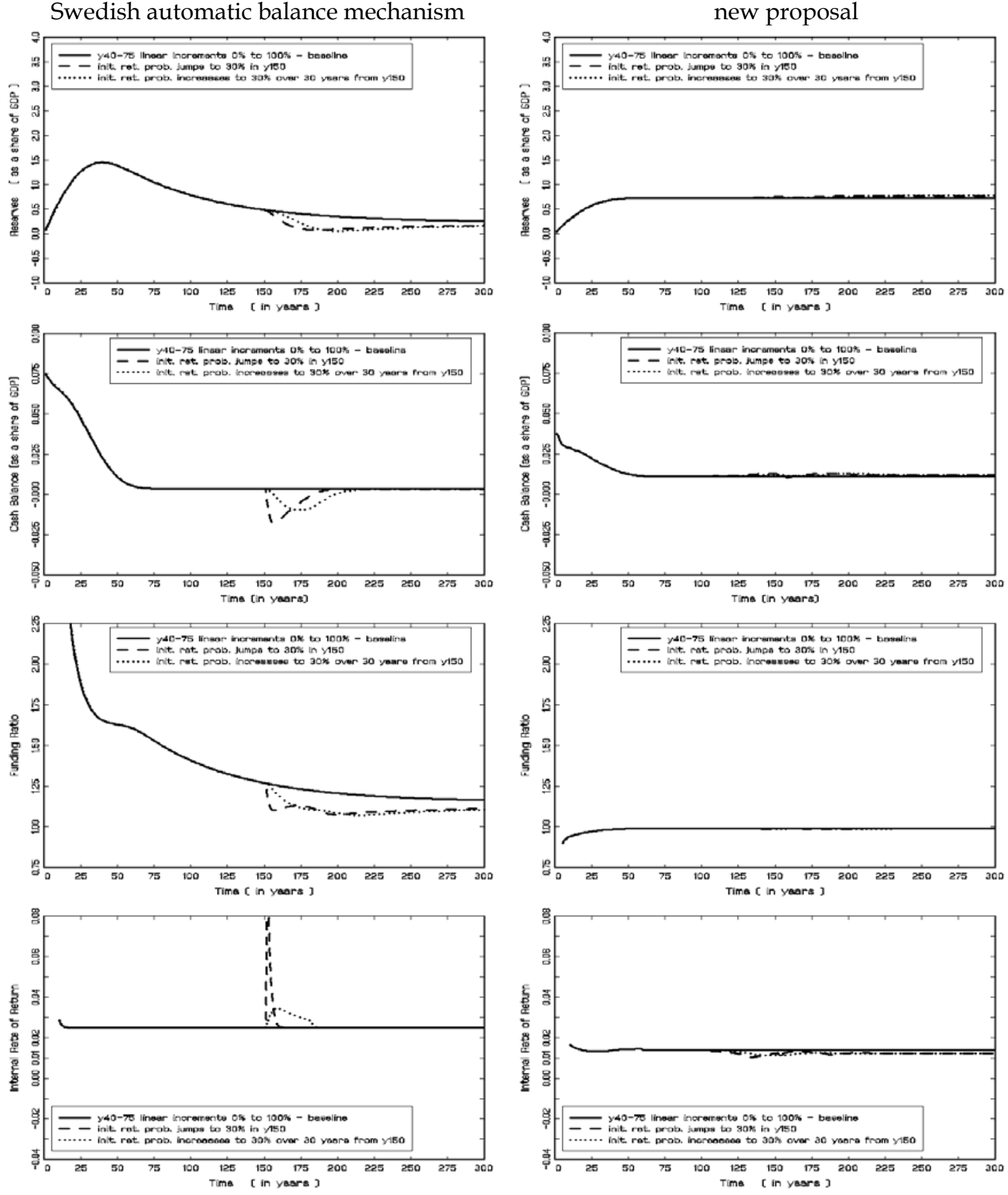
Sensitivity Analysis - Drop-Out Probability Scenarios

Evolution of the Reserves and Balance of the Pension System as a Share of the GDP, the Funding Ratio and Dynamic Internal Rate of Return of the Pension System under the Swedish Automatic Balance Mechanism and the New Indexation Proposal

Swedish automatic balance mechanism
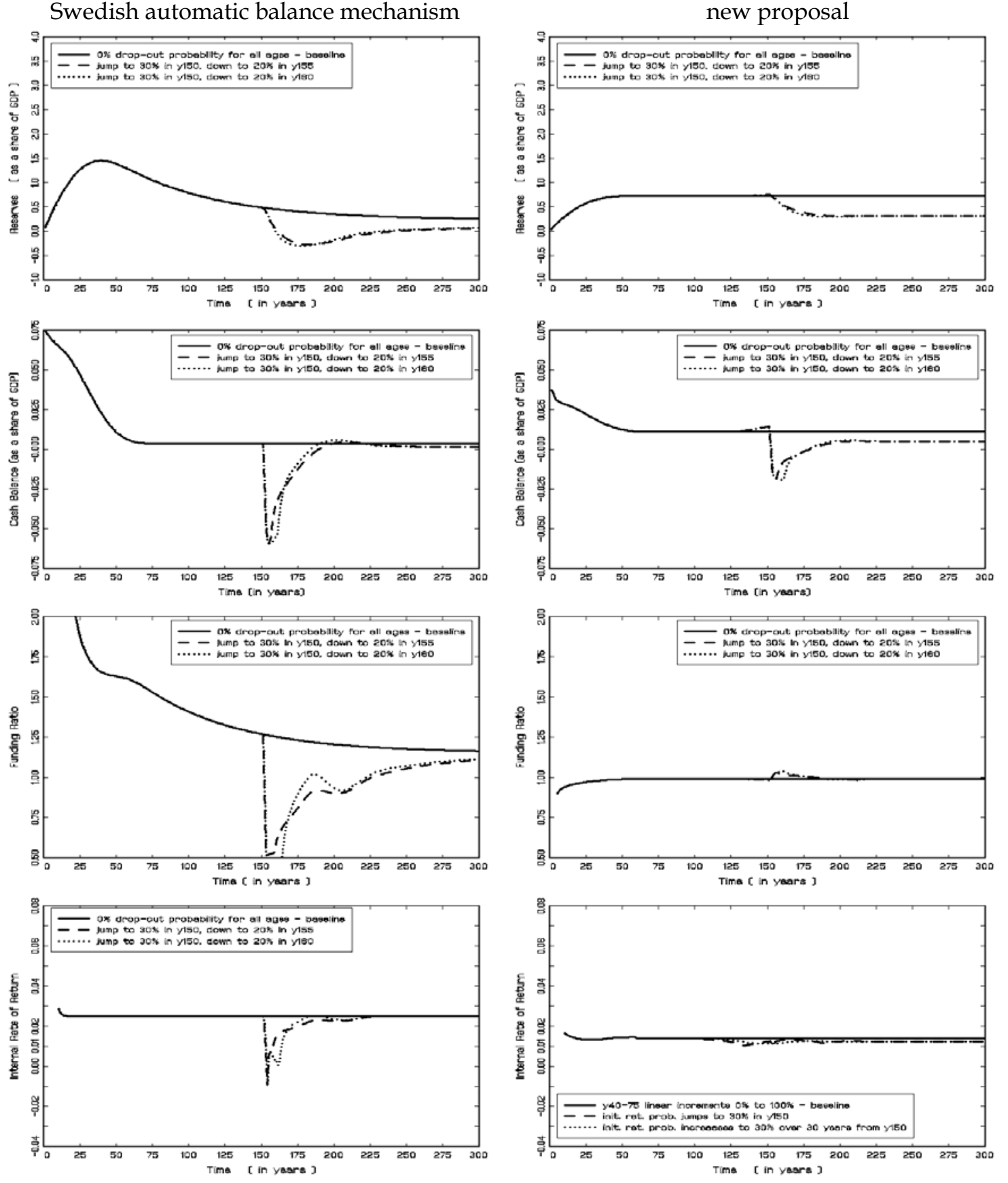